\title{
Roles of Glutamate Receptor $\delta 2$ Subunit (GluR $\delta 2$ ) and Metabotropic Glutamate Receptor Subtype 1 (mGluR1) in Climbing Fiber Synapse Elimination during Postnatal Cerebellar Development
}

\author{
Kouichi Hashimoto, ${ }^{1}$ Ryoichi Ichikawa ${ }^{2}$, Hajime Takechi, ${ }^{3}$ Yoshiro Inoue, ${ }^{4}$ Atsu Aiba, ${ }^{5}$ Kenji Sakimura, ${ }^{6}$ \\ Masayoshi Mishina, ${ }^{7}$ Tsutomu Hashikawa, ${ }^{8}$ Arthur Konnerth, ${ }^{9}$ Masahiko Watanabe, ${ }^{4}$ and Masanobu Kano ${ }^{1}$ \\ ${ }^{1}$ Department of Physiology, Kanazawa University School of Medicine, Takara-machi, Kanazawa 920-8640, Japan, \\ 2Department of Anatomy, Sapporo Medical University, Sapporo 060-8556, Japan, ${ }^{3}$ Department of Gerontology, Kyoto \\ University Faculty of Medicine, Kyoto 606-8507, Japan, ${ }^{4}$ Department of Anatomy, Hokkaido University School of \\ Medicine, Sapporo 060-8638, Japan, 5Division of Cell Biology, Department of Molecular and Cellular Biology, Kobe \\ University Graduate School of Medicine, Kobe 650-0017, Japan, 'Department of Cellular Neurobiology, Brain Research \\ Institute, Niigata University, Niigata 951-8585, Japan, 7 Department of Molecular Neurobiology and Pharmacology, \\ Graduate School of Medicine, University of Tokyo, and Cure Research for Evolutional Science and Technology (CREST), \\ Japan Science and Technology Corporation, Tokyo 113-0033, Japan, ${ }^{8}$ Laboratory for Neural Architecture, Brain Science \\ Institute, RIKEN, Wako-shi, Saitama 351-0198, Japan, and 9/nstitut für Physiologie, Ludwig-Maximilians-Universität \\ München, 80802 München, Germany
}

Climbing fiber (CF) synapse formation onto cerebellar Purkinje cells (PCs) is critically dependent on the synaptogenesis from parallel fibers (PFs), the other input to PCs. Previous studies revealed that deletion of the glutamate receptor $\delta 2$ subunit (GluR82) gene results in persistent multiple CF innervation of PCs with impaired PF synaptogenesis, whereas mutation of the metabotropic glutamate receptor subtype 1 (mGluR1) gene causes multiple CF innervation with normal PF synaptogenesis. We demonstrate that atypical CF-mediated EPSCs (CF-EPSCs) with slow rise times and small amplitudes coexisted with typical CF-EPSCs with fast rise times and large amplitudes in PCs from GluR $\delta 2$ mutant cerebellar slices. CF-EPSCs in mGluR1 mutant and wild-type PCs had fast rise times. Atypical slow CF responses of GluR $\delta 2$ mutant PCs were associated with voltagedependent $\mathrm{Ca}^{2+}$ signals that were confined to PC distal dendrites. In the wild-type and mGluR1 mutant PCs, CF-induced

In the adult cerebellum, each Purkinje cell (PC) is innervated by a single climbing fiber (CF) that originates in the inferior olive and forms strong excitatory synapses onto proximal PC dendrites (Palay and Chan-Palay, 1974; Ito, 1984; Strata and Rossi, 1998). This one-to-one relationship is preceded by a developmental stage of redundant innervation of PCs by multiple CFs (Crépel, 1982). Elimination of supernumerary CFs proceeds in parallel with synaptogenesis onto PCs from parallel fibers (PFs), bifur-

\footnotetext{
Received June 13, 2001; revised Aug. 20, 2001; accepted Sept. 11, 2001.

This work has been partly supported by grants from the Japanese Ministry of Education, Science, Sports, Culture and Technology (M.K.), the Kato Memorial Bioscience Foundation (K.H.), and the Human Frontier Science Program (M.K., A.K.). This work has also been supported by Special Coordination Funds for promoting Science and Technology from the Japanese Government (K.H.) and Research for the Future Program of Japan Society for the Promotion of Science (A.A). We thank Dr. N. Kawai for continuous encouragement throughout the course of this study, K. Matsumoto and Y. Hirano for excellent technical assistance, and T. Hensch for critically reading this manuscript.

Correspondence should be addressed to Masanobu Kano, Department of Physiology, Kanazawa University School of Medicine, Takara-machi, Kanazawa 9208640, Japan. E-mail: mkano@med.kanazawa-u.ac.jp.

Copyright (C) 2001 Society for Neuroscience $\quad 0270-6474 / 01 / 219701-12 \$ 15.00 / 0$
}

$\mathrm{Ca}^{2+}$ signals involved both proximal and distal dendrites. Morphologically, CFs of GluR $\delta 2$ mutant mice extended to the superficial regions of the molecular layer, whereas those of wildtype and mGluR1 mutant mice did not innervate the superficial one-fifth of the molecular layer. It is therefore likely that surplus CFs of GluR $\delta 2$ mutant mice form ectopic synapses onto distal dendrites, whereas those of wild-type and mGluR1 mutant mice innervate proximal dendrites. These findings suggest that GluR $\delta 2$ is required for consolidating PF synapses and restricting CF synapses to the proximal dendrites, whereas the mGluR1-signaling pathway does not affect PF synaptogenesis but is involved in eliminating surplus CF synapses at the proximal dendrites.

Key words: climbing fiber; parallel fiber; cerebellum; Purkinje cell; synapse; glutamate receptor; postnatal development; mutant mouse cated axons of granule cells and the other excitatory input to PCs (Ito, 1984). The importance of PF-PC synapses in CF synapse elimination has been substantiated by the fact that multiple $\mathrm{CF}$ innervation persists in animals with impaired $\mathrm{PF}-\mathrm{PC}$ synaptogenesis, such as X-irradiated rats (Woodward et al., 1974; Crépel and Delhaye-Bouchaud, 1979; Bravin et al., 1995; Sugihara et al., 2000) and agranular cerebellar mutants (weaver, reeler, and staggerer mice) (Crépel and Mariani, 1976; Mariani et al., 1977; Crépel et al., 1980; Mariani and Changeux, 1980).

Glutamate or its related amino acids is considered to be released from $\mathrm{CF}$ and $\mathrm{PF}$ terminals and to activate glutamate receptors (GluRs) on PCs. The GluR $\delta 2$ subunit (GluR $\delta 2$ ) is highly enriched in PCs (Araki et al., 1993; Lomeli et al., 1993) that are localized at the junctional site of $\mathrm{PF}-\mathrm{PC}$ synapses but not at the site of CF-PC synapses (Landsend et al., 1997). In PCs of GluR $\delta 2$-deficient mice, the number of PF-PC synapses is reduced to nearly one-half that of wild-type mice, leaving approximately one-third of PC dendritic spines free of innervation (Kurihara et al., 1997). GluR $\delta 2$-deficient mice display persistent multiple CF innervation, impaired long-term depression (LTD), and motor 
discoordination (Hirano et al., 1995; Kashiwabuchi et al., 1995). The metabotropic GluR subtype 1 (mGluR1) is also abundant in PCs that are localized at the perijunctional site of both the PF-PC and CF-PC (Baude et al., 1993; Nusser et al., 1994). Inactivation of the mGluR1 gene results in persistent multiple CF innervation, impaired LTD, and motor discoordination, without apparent defects in PF-PC synaptogenesis (Aiba et al., 1994; Conquet et al., 1994; Kano et al., 1997; Lévénès et al., 1997; Ichise et al., 2000).

To differentiate the roles of these two GluR molecules in CF synapse formation and elimination, we comparatively examined the GluR $\delta 2$ and mGluR1 mutant mice by recording CF-mediated EPSCs (CF-EPSCs), imaging CF-induced $\mathrm{Ca}^{2+}$ signals in PCs, and labeling CFs anterogradely. We present evidence that surplus CFs form ectopic synapses onto distal dendrites of GluR $\delta 2 \mathrm{mu}-$ tant PCs, whereas CFs innervate proximal dendrites of mGluR1 mutant PCs. These findings suggest that GluR $\delta 2$ is required for consolidating PF synapses and restricting CF synapses to the proximal dendritic domain, whereas the mGluR1-signaling pathway is involved in eliminating excess CF synapses at the proximal dendrites.

\section{MATERIALS AND METHODS}

Animals. The GluR $\delta 2$ mutant mice (Kashiwabuchi et al., 1995) and the mGluR1 mutant mice (Aiba et al., 1994) were produced as described. The GluR $\delta 2$ mutant mice and their littermates were of C57BL $/ 6 \times$ TT2 genetic background (Yagi et al., 1993). The mGluR1 mutant mice and their littermates were of the $129 / \mathrm{Sv} \times \mathrm{C} 57 \mathrm{BL} / 6$ genetic background. Mice were kept in the same room at the animal facility with a $12 \mathrm{hr}$ light/dark cycle. Because we have not found any electrophysiological or morphological difference so far between the wild-type $(+/+)$ mice of C57BL/6 $\times$ TT2 genetic background and those of 129/Sv $\times$ C57BL/6 genetic background, nonmutant $(+/+)$ littermates including both genotypes were used in electrophysiological analyses as wild-type controls.

Electrophysiology. Sagittal cerebellar slices of 200-250 $\mu \mathrm{m}$ thickness were prepared from wild-type, GluR $\delta 2$ mutant, or mGluR1 mutant mice as described previously (Edwards et al., 1989; Llano et al., 1991; Kano and Konnerth, 1992; Aiba et al., 1994). Whole-cell recordings were made from visually identified PCs using a $40 \times$ water-immersion objective attached to either an Olympus (BH-2 or BX50WI, Olympus Optical, Tokyo, Japan) or a Zeiss (Axioskop) upright microscope (Edwards et al., 1989; Llano et al., 1991) at $32^{\circ} \mathrm{C}$. The resistance of patch pipettes was 3-6 $\mathrm{M} \Omega$ when filled with an intracellular solution composed of (in $\mathrm{mM}$ ): 60 $\mathrm{CsCl}, 30 \mathrm{Cs}$ D-gluconate, 20 TEA-Cl, 20 BAPTA, $4 \mathrm{MgCl}_{2}$, 4 ATP, and 30 HEPES; $\mathrm{pH} 7.3$, adjusted with $\mathrm{CsOH}$. The composition of standard bathing solution was (in mM): $125 \mathrm{NaCl}, 2.5 \mathrm{KCl}, 2 \mathrm{CaCl}_{2}, 1 \mathrm{MgSO}_{4}, 1.25$ $\mathrm{NaH}_{2} \mathrm{PO}_{4}, 26 \mathrm{NaHCO}_{3}$, and 20 glucose, bubbled continuously with a mixture of $95 \% \mathrm{O}_{2}$ and $5 \% \mathrm{CO}_{2}$. Bicuculline $(10 \mu \mathrm{M})$ was always present in the saline to block spontaneous IPSCs (Konnerth et al., 1990; Kano et al., 1992). Ionic currents were recorded with either an Axopatch-1D (Axon Instruments, Foster City, CA) or an EPC-9 (HEKA, Lambrecht, Germany) patch-clamp amplifier. The pipette access resistance was compensated as described by Llano et al. (1991). Stimulation and on-line data acquisition were performed using the PULSE software on a Macintosh computer (HEKA). Signals were filtered at $3 \mathrm{kHz}$ and digitized at 20 $\mathrm{kHz}$. The decay phase of EPSCs was fitted with the PULSE-FIT software (HEKA). A glass pipette with a 5- to $10-\mu$ m-diameter tip that was filled with standard saline was used for stimulating CFs. To search for multiple CFs innervating the recorded PC, the stimulation pipette was moved systematically in the granule cell layer, and the stimulus intensity was gradually increased at each stimulation site (pulse width $0.1 \mathrm{msec}$; strength $0-100 \mathrm{~V})$.

$\mathrm{Ca}^{2+}$ imaging. PCs were loaded for at least $20 \mathrm{~min}$ with a $\mathrm{Ca}^{2+}$ indicator (Oregon Green 488 BAPTA-1, Molecular Probes, Eugene, OR; $100 \mu \mathrm{M}$ ) through the patch pipette at room temperature. A high-speed confocal laser-scanning microscope (Noran Odyssey or Oz) attached to an upright microscope (Zeiss Axioskop or Olympus BX50WI) was used to acquire fluorescence images at 30 or $60 \mathrm{~Hz}$ in parallel to the whole-cell recordings (Eilers et al., 1995a; Takechi et al., 1998). Full-frame images were recorded on an optical disk (TQ2026F, Panasonic) and analyzed off-line with the Image-1 software (Universal Image). In some experiments, fluorescence images were acquired at $30 \mathrm{~Hz}$ by using a cooled CCD camera system (IMAGO, T.I.L.L. Photonics, Gräfelfing, Germany) attached to an upright microscope (Zeiss Axioskop). The $\mathrm{Ca}^{2+}$ dependent fluorescence signals from selected regions of interest were background corrected and expressed as increases in fluorescence divided by the prestimulus fluorescence values $\left(\Delta F / F_{0}\right)$ using Igor Pro software (Wavemetrics). In PCs with multiple CF innervation, it was often difficult to detect $\mathrm{CF}$-induced $\mathrm{Ca}^{2+}$ signals under normal resting potentials with an extracellular $\mathrm{Ca}^{2+}$ concentration of $2 \mathrm{~mm}$. This was presumably because the CF-induced EPSPs were too small to evoke spikes or, even if they induced spikes, the associated $\mathrm{Ca}^{2+}$ entry was too small to be detected. In these cases, we depolarized the PCs by constant current injection so that CF-EPSPs evoked spikes and increased the extracellular $\mathrm{Ca}^{2+}$ concentration to $3 \mathrm{mM}$.

Anterograde labeling of CFs. Under deep anesthesia with chloral hydrate $(350 \mathrm{mg} / \mathrm{kg}$ of body weight), a glass pipette (inner tip diameter $10-20 \mu \mathrm{m}$ ) filled with $2-3 \mu \mathrm{l}$ of a $10 \%$ solution of biotinylated dextran amine (10,000 molecular weight; Molecular Probes) in $0.01 \mathrm{M} \mathrm{PBS,} \mathrm{pH}$ 7.4 , was inserted into the right inferior olive by dorsal approach (Rossi et al., 1995). Biotinylated dextran amine was injected iontophoretically by positive current $(7 \mu \mathrm{A}$ for $30 \mathrm{~min}$ with a protocol of $700 \mathrm{msec}$ on and $1300 \mathrm{msec}$ off). After 6-8 d of survival, mice were anesthetized with chloral hydrate $(350 \mathrm{mg} / \mathrm{kg})$ and perfused transcardially with $4 \%$ paraformaldehyde in $0.1 \mathrm{~m}$ phosphate buffer, $\mathrm{pH}$ 7.4. Coronal brainstem sections were examined to check the injection site of biotinylated dextran amine. Mice with the injection site restricted to the caudal part of the medial accessory olive were chosen for the preparation of microslicer cerebellar sections (50 $\mu \mathrm{m}$ in thickness). Parasagittal cerebellar sections were incubated overnight in avidin-peroxidase (Amersham Biosciences, Buckinghamshire, UK) diluted with PBS containing $1 \%$ Tween 20 and visualized with diaminobenzidine and cobalt. Low-power photographs were taken with a Normarski interference contrast microscope (Axiophoto, Zeiss), whereas high-power ones were taken with a bright-field microscope (AX-80, Olympus). To quantity the extent of arbors of labeled CFs, the relative vertical height of the most distal tip was measured for at least $30 \mathrm{CFs}$ in each mouse and expressed as the percentage of the molecular layer thickness. In each genotype, the mean value and SEM were obtained from three mice, and the difference between the genotypes was tested by Student's $t$ test.

\section{RESULTS}

\section{A novel slow time course CF-EPSC in GluR $\delta 2$ mutant PCs}

In parasagittal cerebellar slices, PCs were recorded in the wholecell configuration, and CFs were stimulated with a glass pipette placed in the granule cell layer near the recorded PCs (Aiba et al., 1994; Kano et al., 1995, 1997). To search PCs with multiple CF innervation, the stimulation pipette was systematically moved by $\sim 20 \mu \mathrm{m}$ steps, and the stimulus intensity was gradually increased at each stimulation site (pulse width $0.1 \mathrm{msec}$; strength 0-100 V) (Kano et al., 1995, 1997, 1998; Offermanns et al., 1997; Watase et al., 1998; Ichise et al., 2000). EPSCs were elicited in an all-or-none fashion in most of wild-type PCs (Fig. $1 A$ ), whereas EPSCs with more than one discrete step were recorded in mGluR1 mutant PCs (Fig. 1B) with much higher incidence than in wild-type PCs (Kano et al., 1997; Lévénès et al., 1997; Ichise et al., 2000). These EPSCs displayed clear paired-pulse depression (PPD) to a stimulus pair with varying interpulse intervals (Fig. 2A,B, wild-type) (Konnerth et al., 1990; Aiba et al., 1994; Kano et al., 1995, 1997; Hashimoto and Kano, 1998).

In the GluR $\delta 2$ mutant mice, stimulation in the granule cell layer elicited multiple EPSCs in 88 of 122 PCs (Fig. 1C). Each of these multiple EPSCs displayed clear PPD to a similar or greater extent than that of wild-type CF-EPSCs (Fig. 2A,B, GluR $\delta 2$ mutant). These multiple EPSCs in GluR $\delta 2$ mutant PCs were judged to be elicited by stimulating CFs and not by activating mossy fiber-granule cell-PF circuits, because EPSCs elicited by PF stimulation display clear paired-pulse facilitation in GluR $\delta 2$ 

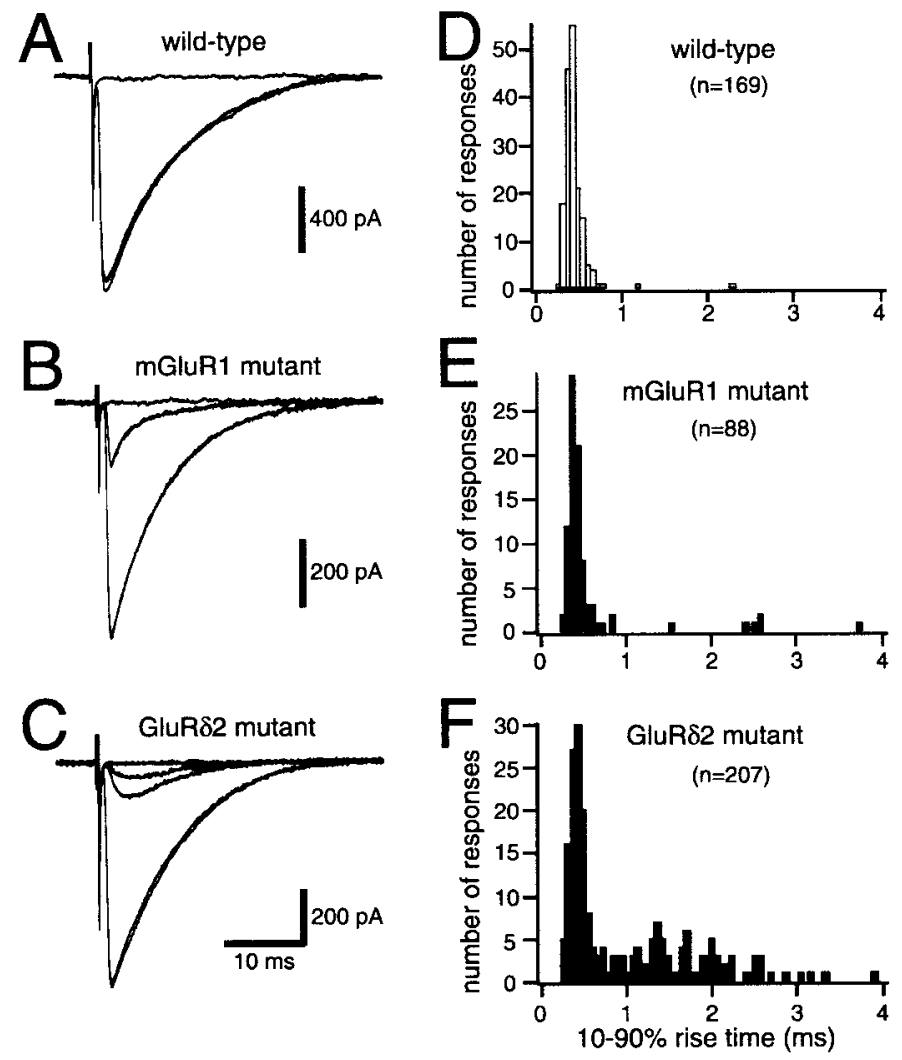

Figure 1. Time course of CF-EPSCs in wild-type, mGluR1 mutant, and GluR $\delta 2$ mutant PCs. $A-C$, EPSCs elicited by stimulation of CFs in the granule cell layer in a wild-type $(A, \mathrm{P} 28)$, a mGluR1 mutant $(B, \mathrm{P} 49)$, and a GluR $\delta 2$ mutant $(C$, P64) PC. With gradually increasing stimulus intensities, EPSCs of the wild-type were elicited in an all-or-none fashion $(A)$, whereas those of the mGluR1 mutant $(B)$ and the GluR $\delta 2$ mutant $(C)$ occurred at multiple discrete steps, indicating that they were innervated by multiple CFs. Note that the rise time of the largest CF-EPSC of the GluR $\delta 2$ mutant is similar to that of the wild-type or the mGluR1 mutant CF-EPSC, whereas the rise times of the smaller two CF-EPSCs of the GluR $\delta 2$ mutant are significantly slower. One to three traces are superimposed at each threshold intensity. Stimuli were applied at $0.2 \mathrm{~Hz}$. Holding potentials were $-10 \mathrm{mV}$ for both the wild-type and GluR $\delta 2$ mutant PCs and $-20 \mathrm{mV}$ for the mGluR1 mutant PC to inactivate voltage-dependent conductances. $D-F$, Summary histograms showing the $10-90 \%$ rise time of CF-EPSCs in wild-type $(D)$, mGluR1 mutant $(E)$, and GluR $\delta 2$ mutant $(F)$ PCs. Data were obtained from mice at P23-P70.

mutant PCs as in wild-type PCs (Kashiwabuchi et al., 1995; Kurihara et al., 1997). These results indicate that most of the GluR $\delta 2$ mutant PCs were innervated by multiple CFs.

In the multiple CF-EPSCs of the GluR $\delta 2 \mathrm{PC}$ shown in Figure $1 C$, the time course was significantly slower for the smaller two EPSCs than for the largest EPSC. The 10-90\% rise time of the wild-type CF-EPSCs displayed a normal distribution with a peak around $0.5 \mathrm{msec}(0.46 \pm 0.11 \mathrm{msec}$; mean $\pm \mathrm{SD} ; n=105)$ (Fig. $1 D)$. That of the mGluR1 mutant had a similar distribution $(0.57 \pm 0.58$ msec; mean $\pm \mathrm{SD} ; n=88)($ Fig. $1 E)$. In contrast, the rise time of GluR $\delta 2$ mutant CF-EPSCs segregated into two distinct populations (Fig. $1 F)$. The mean value for the fast $(<1.0$ $\mathrm{msec})$ population was $0.48 \mathrm{msec}( \pm 0.15 \mathrm{msec} \mathrm{SD} ; n=127)$, which was similar to wild-type, whereas that for the slow $(>1.0 \mathrm{msec})$ population was $1.81 \mathrm{msec}( \pm 0.59 \mathrm{msec} \mathrm{SD} ; n=80)$. These results suggest that GluR $\delta 2$ mutants have two distinct populations of CF inputs in terms of the EPSC rise time. The CF-EPSCs with fast
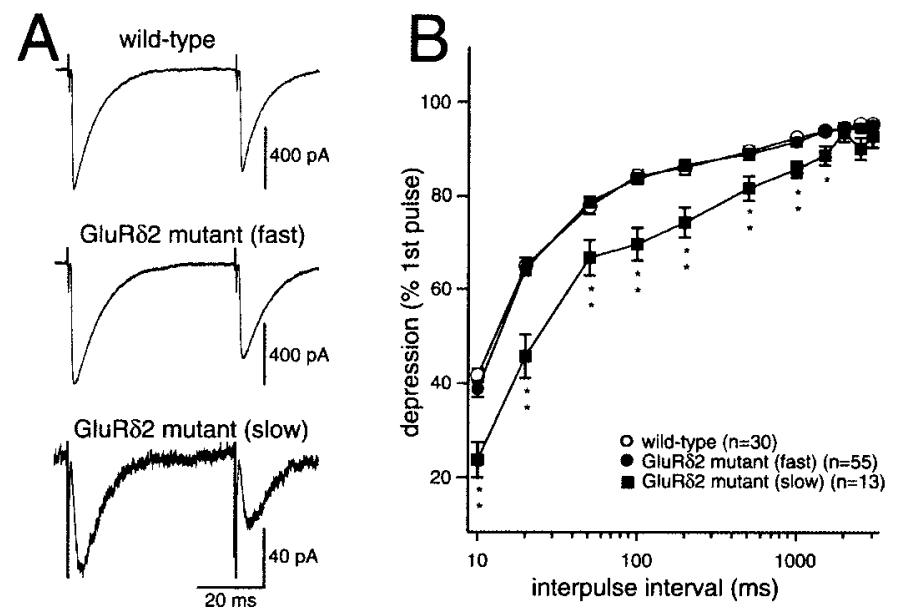

Figure 2. Paired-pulse depression of CF-EPSCs in the wild-type and GluR $\delta 2$ mutant PCs. $A$, Single-sweep examples of paired-pulse depression (interpulse interval of $50 \mathrm{msec}$ ) of CF-EPSCs from a wild-type (top panel, P28) and a GluR $\delta 2$ mutant (middle and bottom panels, P62) PC. The fast (middle panel) and slow (bottom panel) CF-EPSCs were elicited separately from the same GluR $\delta 2$ mutant PC. Stimulus pairs were applied at $0.2 \mathrm{~Hz}$. Holding potential was $-10 \mathrm{mV}$ for all cells. $B$, Summary graphs showing paired-pulse depression for the wild-type $(\bigcirc)$, the fast GluR $\delta 2$ mutant (O), and the slow GluR $\delta 2$ mutant (ם) CF-EPSCs. The second response (expressed as a percentage of response to the first pulse; mean \pm SEM) is plotted as a function of interpulse interval. Stimulus pairs were applied at 0.2 Hz. ${ }^{* *} p<0.01 ;{ }^{*} p<0.05$, compared with the values of the wild-type CF-EPSCs (Student's $t$ test).

rise time were similar to those of wild-type and mGluR1 mutant mice, whereas the slower CF-EPSCs appear to be unique to GluR $\delta 2$ mutant PCs. We also measured the decay time constant of CF-EPSCs in the three strains of mice by fitting the CF-EPSC decay with single exponentials (Llano et al., 1991; Aiba et al., 1994; Kano et al., 1995, 1997). The decay time constants of CF-EPSCs in wild-type and GluR $\delta 2$ mutant mice were not significantly different, being $6.73 \mathrm{msec}( \pm 2.04 \mathrm{msec} ; n=84)$ for wild-type and $6.48 \mathrm{msec}( \pm 2.92 \mathrm{msec} ; n=174)$ for the GluR $\delta 2$ mutant. The decay time constants were $4.75 \mathrm{msec}( \pm 2.36 \mathrm{msec}$; $n=88$ ) for the mGluR1 mutant, which is significantly shorter than wild-type mice as reported previously (Aiba et al., 1994; Kano et al., 1997).

The GluR $\delta 2$ mutant PCs could be classified into four categories in terms of the pattern of $\mathrm{CF}$ innervation. These are as follows: (1) PC innervated by a single CFs that generates typical fast CF-EPSCs (Fig. 3A); (2) PC multiple-innervated by more than one CF that generates fast CF-EPSCs (Fig. 3B); (3) PC multiple-innervated by one $\mathrm{CF}$ that generates fast $\mathrm{CF}$-EPSCs and one or more CFs that generate slow CF-EPSCs (Fig. 3C); and (4) $\mathrm{PC}$ multiple-innervated by more than one $\mathrm{CF}$ that generates fast CF-EPSCs and one or more CFs that generate slow CF-EPSCs (Fig. 3D). Frequency distribution of all PCs in terms of number of CF-EPSC steps indicates that $72.1 \%$ of PCs in GluR $\delta 2$ mutant mice were innervated by multiple CFs (Fig. $3 E$ ). The histogram constructed only from PCs without slow CF-EPSCs indicates that $36.2 \%$ of such PCs were innervated by two CFs and $5.2 \%$ by three CFs (Fig. $3 F$ ). On the other hand, the histogram constructed only from PCs with slow CF-EPSCs shows that most of the PCs were multiple-innervated (Fig. 3G). In particular, 68.7\% are innervated by three or more CFs (Fig. $3 G$ ). These results indicate that the existence of the slow CF-EPSCs significantly contributes to 


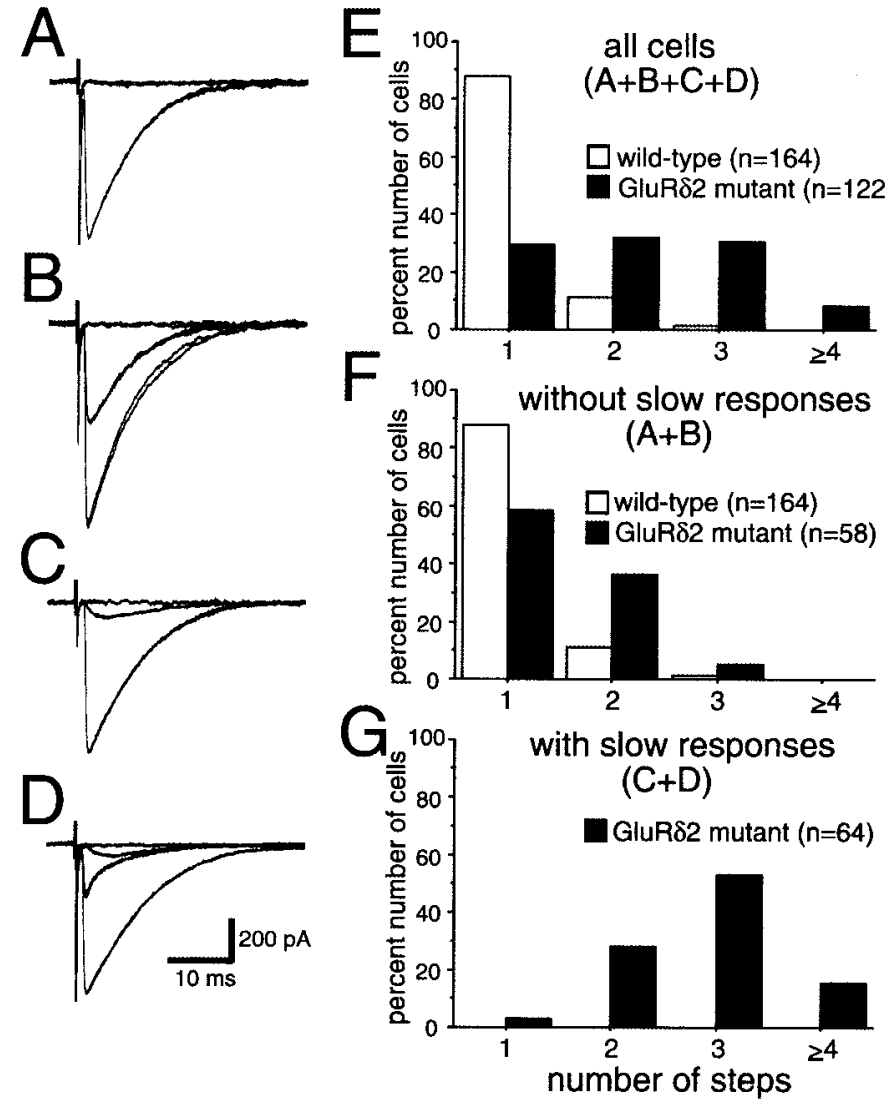

Figure 3. Four patterns of CF innervation in GluR $\delta 2$ mutant PCs. $A-D$, Sample records of GluR $\delta 2$ mutant CF-EPSCs representing four distinct CF innervation patterns. $A$, Single fast CF-EPSC; $B$, multiple fast CFEPSCs; $C$, single fast plus one or more slow CF-EPSCs; $D$, multiple fast plus one or more slow CF-EPSCs. One to three traces are superimposed at each threshold intensity. Stimuli were applied at $0.2 \mathrm{~Hz}$. Holding potentials were $-10 \mathrm{mV}$ for $A, C$, and $D$ and $-20 \mathrm{mV}$ for $B . E-G$, Summary histograms showing the number of discrete steps of CF-EPSCs for all PCs $(E)$, for PCs without slow EPSCs $(F)$, and for PCs with slow EPSCs $(G)$. Open and filled columns represent the wild-type and GluR $\delta 2$ mutant PCs, respectively. Data were obtained from mice at P24-P64.

the high percentage of multiple-innervated PCs in the GluR $\delta 2$ mutant mice.

\section{Slow CF-EPSCs of GluR $\delta 2$ mutant PCs appear during the second postnatal week}

In rodents, PF synaptogenesis onto PC dendrites is known to continue postnatally up to approximately postnatal day (P) 20 (Altman and Bayer, 1997). The structure of the PF-PC synapse is immature around P7, when no significant differences in the morphology and electrophysiology are found between the wild-type and GluR $\delta 2$ mutant mice (Kurihara et al., 1997). Impaired PF synapse formation is obvious in the GluR $\delta 2$ mutant mouse at P14 (Kurihara et al., 1997). In contrast, PF-PC synapse formation appears normal in mGluR1 mutant mice (Kano et al., 1997). We followed the developmental course of CF-EPSCs in the three strains of mice to examine whether the impaired PF synapse formation correlated with the appearance of atypical slow $\mathrm{CF}$ EPSCs in GluR $\delta 2$ mutant mice.

The 10-90\% rise time of the wild-type CF-EPSC was longer during P3-P9 than at later developmental stages (Fig. 4A) $(1.0 \pm$ 0.4 msec; mean $\pm \mathrm{SD} ; n=43)$. The rise times of the mGluR1 mutant and GluR 82 mutant CF-EPSCs from P3 to P9 had a
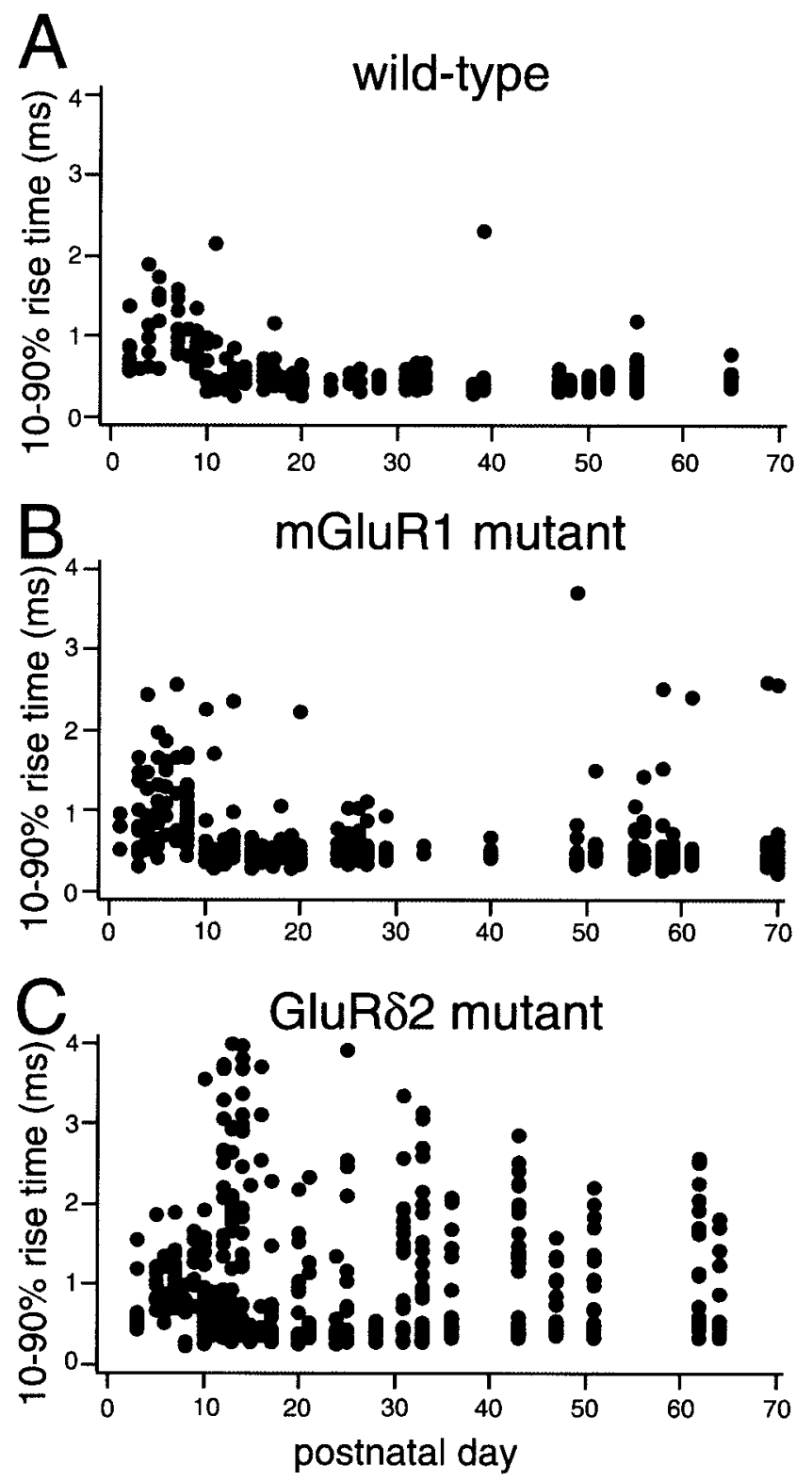

Figure 4. Postnatal change of CF-EPSC time course in the three strains of mice. The $10-90 \%$ rise times of CF-EPSCs are plotted against postnatal day for wild-type $(A)$, mGluR1 mutant $(B)$, and GluR $\delta 2$ mutant $(C)$ PCs. Note that CF-EPSCs have similar rise times in the three strains of mice during $\mathrm{P} 3-\mathrm{P} 9$, whereas those with significantly slower rise times are obvious after $\mathrm{P} 10$ in the GluR $\delta 2$ mutant.

similar distribution $(1.0 \pm 0.5 \mathrm{msec}, n=71$ for the mGluR1 mutant; $0.9 \pm 0.4 \mathrm{msec}, n=64$ for the GluR $\delta 2$ mutant) (Fig. $4 B, C)$ to that of wild-type. During P10-P14, the rise times of the wild-type and mGluR1 mutant CF-EPSCs decreased to adult levels (Fig. 4A,B). In contrast, CF-EPSCs with significantly slower rise times appeared during P10-P14 in the GluR $\delta 2$ mutant (Fig. 4C). These data indicate that atypical slow CF-EPSCs become evident during the second postnatal week when a defect in the PF to PC synapse formation occurs in the GluR $\delta 2$ mutant mouse.

\section{Electrophysiological properties of slow CF-EPSC in GluRס2 mutant PCs}

To examine whether the CF-EPSC amplitudes of mGluR1 mutant and GluR $\delta 2$ mutant mice differ from those of wild-type mice, the 

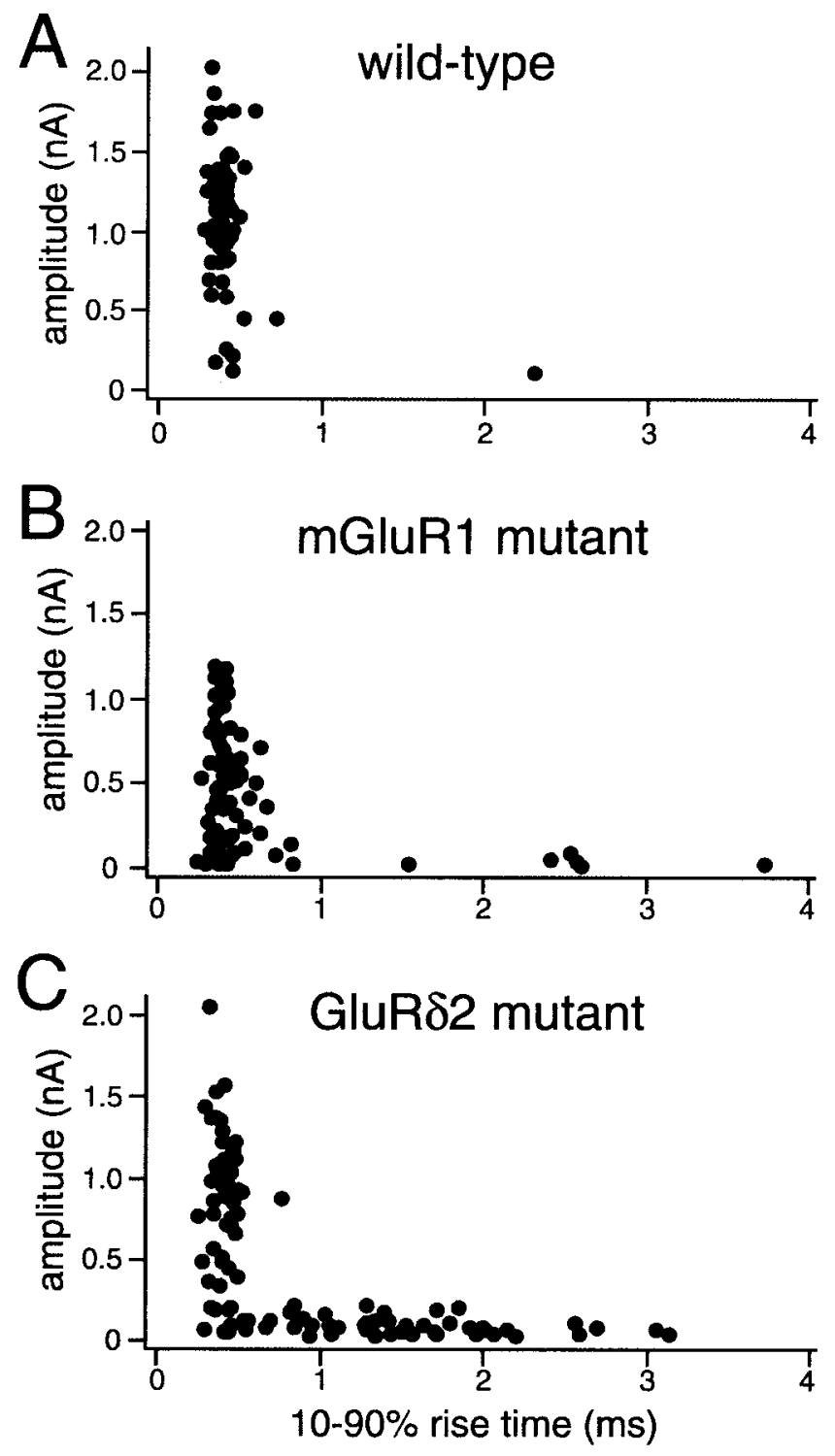

Figure 5. Two distinct populations of CF-EPSCs in the GluR $\delta 2$ mutant mice. The amplitudes of CF-EPSCs (measured at a holding potential of $-10 \mathrm{mV})$ are plotted against the $10-90 \%$ rise time for wild-type $(A)$, mGluR1 mutant $(B)$, and GluR $\delta 2$ mutant $(C)$ mice. Note that two distinct populations of CF-EPSCs, those with a fast rise time and relatively large amplitude and those with a slow rise time and small amplitude, were evident in $C$.

peak amplitudes of CF-EPSCs were measured at a fixed holding potential $(-10 \mathrm{mV})$. In cases of multiple-innervated PCs (Fig. $1 B, C)$, the amplitude of a given CF-EPSC was measured by digitally subtracting other CF-EPSCs that were induced by lower stimulus strength. The peak CF-EPSC amplitude was plotted against the $10-90 \%$ rise time. CF-EPSCs in wild-type (Fig. $5 A$ ) and mGluR1 mutant (Fig. $5 B$ ) mice were in a single population with only a few CF-EPSCs with slow rise time and small amplitude. In contrast, two distinct populations of CF-EPSCs, those with fast rise time and relatively large amplitude and those with slow rise time and small amplitude, were present in GluR $\delta 2$ mutant mice (Fig. 5C).

We examined other electrophysiological and pharmacological properties of atypical slow CF-EPSCs of GluR $\delta 2$ mutant PCs. They displayed a linear current-voltage $(I-V)$ relationship (data
Table 1. Passive properties of PCs

\begin{tabular}{lcc} 
& $\begin{array}{c}\text { Wild-type } \\
(n=9)\end{array}$ & $\begin{array}{c}\text { GluR } 82 \text { mutant } \\
(n=11)\end{array}$ \\
\hline $\mathrm{C} 1(\mathrm{pF})$ & $73.8 \pm 12.9$ & $67.2 \pm 20.3$ \\
$\mathrm{C} 2(\mathrm{pF})$ & $684 \pm 101^{* *}$ & $513 \pm 75.2^{* *}$ \\
$\mathrm{R} 1(\mathrm{M} \Omega)$ & $9.3 \pm 1.3$ & $7.9 \pm 2.4$ \\
$\mathrm{R} 2(\mathrm{M} \Omega)$ & $10.6 \pm 2.7^{*}$ & $14.9 \pm 4.6^{*}$ \\
$\mathrm{R} 3(\mathrm{M} \Omega)$ & $145.7 \pm 41.5^{* *}$ & $212.8 \pm 47.1^{* *}$
\end{tabular}

Parameters were calculated on the basis of the model described by Llano et al. (1991), which distinguishes two regions of PCs: region 1 representing the soma and the main proximal dendrites, and region 2 representing the dendritic tree. $\mathrm{C} 1$ represents the lumped membrane capacitance of region 1, and R1 represents the pipette access resistance. Region 2 is linked to region 1 by resister R2, which represents the lumped resistance between the main proximal dendrite and each membrane region of the distal dendrites. $\mathrm{C} 2$ and $\mathrm{R} 3$ represent the lumped capacitance and resistance, respectively, of the dendritic tree of PCs. Data are expressed as mean \pm SD. ${ }^{* *} p<0.01 ;{ }^{*} p<0.05$ (two-tailed $t$ test).

not shown). In $\mathrm{Mg}^{2+}$-free saline containing glycine $(10 \mu \mathrm{M})$, atypical slow CF-EPSCs were not affected by an NMDA receptor antagonist, DL-2-amino-5-phosphonopentanoate $\left(\begin{array}{lll}50 & \mu \mathrm{M}\end{array}\right)$ but were totally suppressed by a non-NMDA antagonist, 6-cyano-7nitroquinoxaline-2,3-dione $(10 \mu \mathrm{M})$ (data not shown). These results indicate that atypical CF-EPSCs of GluR $\delta 2$ mutant PCs are mediated exclusively by non-NMDA receptors, which is similar to typical CF-EPSCs of wild-type and those of GluR $\delta 2$ PCs (Kashiwabuchi et al., 1995).

\section{Passive membrane properties of GluR $\delta 2$ mutant PCs}

It has been shown morphologically that CF synapses are located on the proximal dendrites of PCs, whereas PF synapses oppose spines at the distal dendrites (Palay and Chan-Palay, 1974; Ito, 1984; Strata and Rossi, 1998). The $10-90 \%$ rise times of PFEPSCs are significantly slower than those of CF-EPSCs in both the rat (Llano et al., 1991) and mouse (Aiba et al., 1994; Kano et al., 1995, 1997), suggesting that the EPSC rise time in PCs reflects the electrotonic length from the soma to the site of the synapse. It is likely, therefore, that the atypical slow CF-EPSCs in GluR $\delta 2$ mutant PCs arise from synapses located electrotonically distant from the soma, presumably on the distal dendrites. Because the EPSC rise time depends on the passive membrane properties, we compared several parameters of wild-type and GluR $\delta 2$ mutant $\mathrm{PCs}$ in response to hyperpolarizing voltage steps from -70 to $-80 \mathrm{mV}$. As reported previously in rat PCs (Llano et al., 1991), the decay of the current was biphasic and could be described by the sum of two exponentials in both wild-type and GluR $\delta 2$ mutant PCs (data not shown). The time constants for the fast $(\tau 1)$ and slow $(\tau 2)$ components were $0.35 \pm 0.04$ and $13.4 \pm 1.9 \mathrm{msec}$ (mean $\pm \mathrm{SD} ; n=9$ ) for the wild-type and $0.33 \pm 0.11$ and $11.6 \pm$ $2.0 \mathrm{msec}(n=11)$ for the GluR $\delta 2$ mutant. Both $\tau 1$ and $\tau 2$ values were not significantly different between the wild-type and the GluR $\delta 2$ mutant ( $p>0.05$; Student's $t$ test). We then calculated several parameters representing passive properties of PCs based on the model equivalent circuit of PCs described by Llano et al. (1991) (Table 1). As shown in Table 1, the lumped dendritic capacitance (C2) was smaller $(p<0.01$; Student's $t$ test) and lumped resistances were larger $(p<0.05$ for $\mathrm{R} 2 ; p<0.01$ for $\mathrm{R} 3$; Student's $t$ test) in the GluR $\delta 2$ mutant than in the wild-type mice. These results suggest that the average total membrane area of the dendritic tree of the GluR $\delta 2$ mutant PCs is smaller than that of wild-type PCs. This is consistent with morphological data that the molecular layer of the GluR $\delta 2$ mutant is thinner than that of 

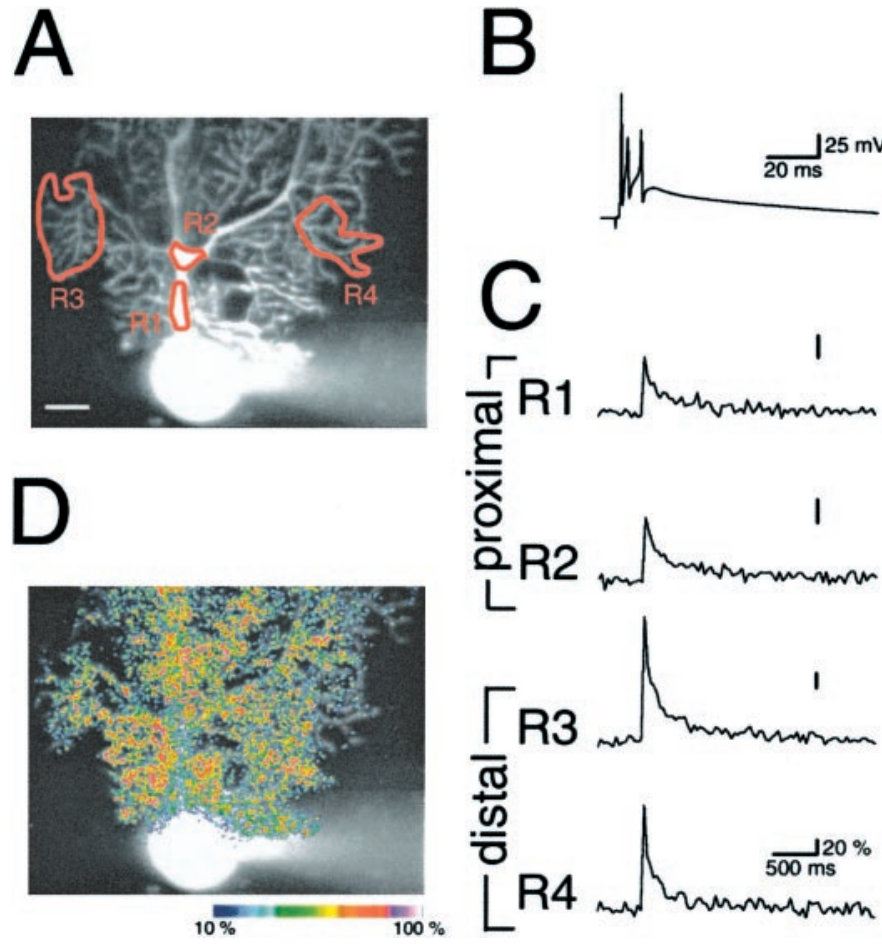

Figure 6. CF-induced $\mathrm{Ca}^{2+}$ transients in a mono-innervated wild-type PC. $A$, Reconstructed image of a wild-type PC. R1-R4 indicate the dendritic regions from which the $\mathrm{Ca}^{2+}$ signals shown in $C$ are measured. Scale bar, $20 \mu \mathrm{m}$. $B$, Complex spike induced by CF stimulation under the current-clamp recording mode. $C$, Time course of $\mathrm{CF}$-induced $\mathrm{Ca}^{2+}$ signals measured in the regions indicated in $A$. $D$, Pseudocolor image showing the relative increase in $\mathrm{Ca}^{2+}$-dependent fluorescence $\left(\Delta F / F_{0}\right)$ evoked by CF stimulation. For this and the following figures (Figs. 7-9), the $\Delta F / F_{0}$ values for pseudocolor images were calculated from the prestimulus and poststimulus fluorescent values that were obtained by averaging five consecutive images (132 msec periods) just before and after CF stimulation.

the wild-type cerebellum (Kurihara et al., 1997). These results indicate that the slow rise times of a subpopulation of GluR $\delta 2$ mutant CF-EPSCs cannot be explained by the altered passive properties of the PC dendrites.

\section{Imaging CF-induced $\mathrm{Ca}^{2+}$ transients suggests that slow CF-EPSCs of GluR 22 mutant PCs arise from synapses located at distal dendrites}

We measured $\mathrm{Ca}^{2+}$ signals associated with $\mathrm{CF}$ responses by using a high-speed confocal laser-scanning microscope or a cooled CCD camera system. Whole-cell recording from PCs was conducted simultaneously with the $\mathrm{Ca}^{2+}$ imaging. The $\mathrm{Ca}^{2+}$ signals were measured in small regions at three different levels of PC dendritic arborization: the primary smooth branch, the tertiary smooth branch, and terminal branchlets. In the following figures, the primary and tertiary smooth branches are collectively termed "proximal dendrites," and the terminal branchlets are termed "distal dendrites." In wild-type animals, it is shown morphologically that CFs form extensive synaptic contacts onto proximal dendrites, whereas PFs form en passant synapses onto spines of distal dendrites (Palay and Chan-Palay, 1974; Ito, 1984; Strata and Rossi, 1998).

In the mono-innervated wild-type PC (Fig. 6A), stimulation of the $\mathrm{CF}$ induced a typical complex spike (Fig. $6 B$ ) that accompanied a clear $\mathrm{Ca}^{2+}$ signal over the entire dendritic tree (Fig. $\left.6 C, D\right)$.
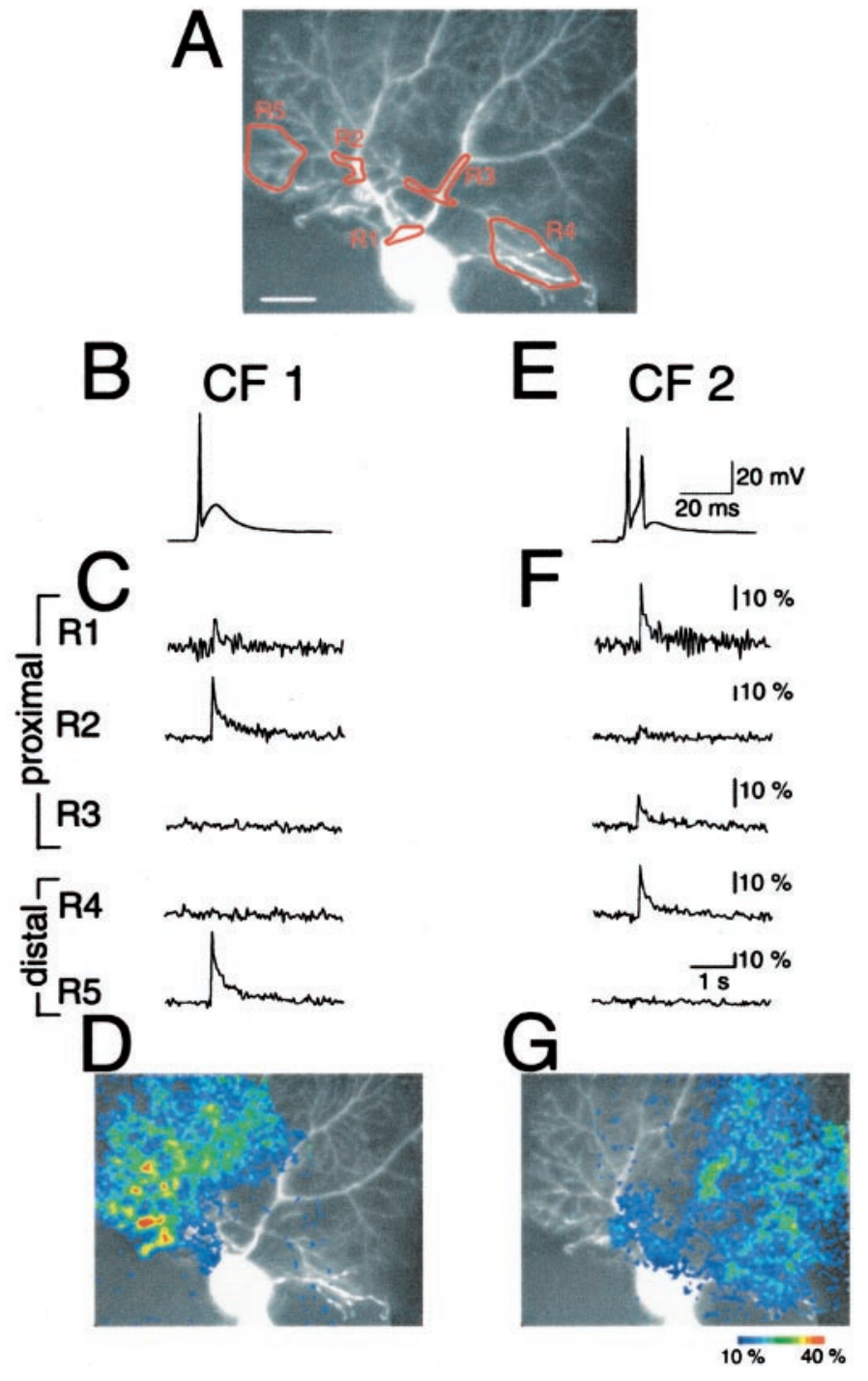

Figure 7. $\mathrm{CF}$-induced $\mathrm{Ca}^{2+}$ transients in a double-innervated mGluR1 mutant PC. $A$, Reconstructed image of a mGluR1 mutant PC. R1-R5 indicate the dendritic regions from which the $\mathrm{Ca}^{2+}$ signals shown in $C$ and $F$ are measured. Scale bar, $20 \mu \mathrm{m} . B, E$, Responses induced by stimulating two different CFs, CF1 $(B)$ and $\mathrm{CF} 2(E)$, under the current-clamp recording mode. $C, F$, Time course of $\mathrm{Ca}^{2+}$ signals measured in the regions indicated in $A$ in response to stimulation of $\mathrm{CF} 1(C)$ and $\mathrm{CF} 2(F)$. $D, G$, Pseudocolor images showing the relative increase in $\mathrm{Ca}^{2+}$. dependent fluorescence $\left(\Delta F / F_{0}\right)$ evoked by CF1 $(D)$ and CF2 $(G)$ stimulation.

The $\mathrm{Ca}^{2+}$ rose in both proximal $(R 1, R 2)$ and distal $(R 3, R 4)$ dendrites (Fig. $6 C, D$ ). In the double-innervated mGluR1 mutant PC (Fig. 7A), stimulation of each CF induced a large EPSP with spike(s) (Fig. $7 B, E$ ) and induced a clear $\mathrm{Ca}^{2+}$ transient (Fig. $7 C, F)$. Stimulation of one $\mathrm{CF}(C F 1)$ caused elevation of $\mathrm{Ca}^{2+}$ that was confined to the left dendritic tree (Fig. $7 C, D$ ), whereas stimulation of the other $\mathrm{CF}(C F 2)$ caused $\mathrm{Ca}^{2+}$ transients in the right dendritic tree (Fig. $7 F, G$ ). It should be noted that $\mathrm{Ca}^{2+}$ was elevated in both proximal and distal portions of each dendritic tree. In 14 multiple-innervated mGluR1 mutant PCs, CF-induced $\mathrm{Ca}^{2+}$ signals always involved proximal dendrites. In 16 monoinnervated PCs from mGluR1 mutant mice, the pattern of CFinduced $\mathrm{Ca}^{2+}$ signals was identical to that of the monoinnervated wild-type PCs (data not shown). These results suggest 

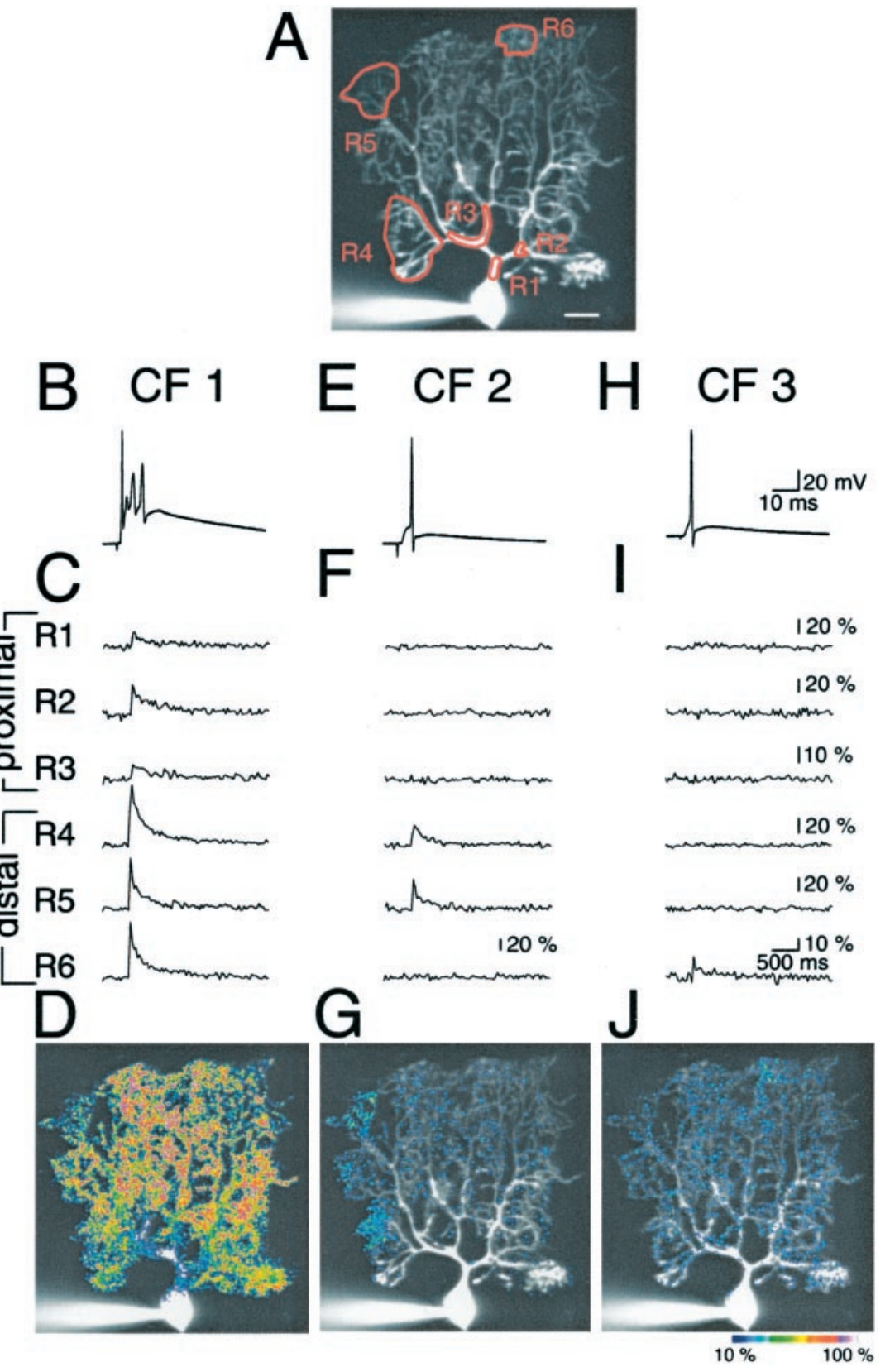

Figure 8. CF-induced $\mathrm{Ca}^{2+}$ transients in a multipleinnervated GluR $\delta 2$ mutant PC. $A$, Reconstructed image of a GluR 82 mutant PC. R1-R6 indicate the dendritic regions from which the $\mathrm{Ca}^{2+}$ signals shown in $C, F$, and $I$ are measured. Scale bar, $20 \mu \mathrm{m}$. $B, E, H$, Responses induced by stimulating three different CFs, CF1 $(B), \mathrm{CF} 2$ $(E)$, and $\mathrm{CF} 3(H)$, under the current-clamp recording mode. $C, F, I$, Time course of $\mathrm{Ca}^{2+}$ signals measured in the regions indicated in $A$ in response to stimulation of CF1 $(C)$, CF2 $(F)$, or CF3 $(I) . D, G, J$, Pseudocolor images showing the relative increase in $\mathrm{Ca}^{2+}$-dependent fluorescence $\left(\Delta F / F_{0}\right)$ evoked by CF1 $(D), \mathrm{CF} 2(G)$, or CF3 $(J)$ stimulation. that mGluR1 mutant PCs are innervated by CFs at proximal dendrites as wild-type PCs whether they are mono- or multipleinnervated. The $\mathrm{Ca}^{2+}$ signals in the distal dendrite presumably reflected the spread of depolarization and activation of voltagegated $\mathrm{Ca}^{2+}$ channels.

In GluR $\delta 2$ mutant PCs, we detected different pattern of CFinduced $\mathrm{Ca}^{2+}$ signals from those seen in wild-type or mGluR1 mutant PCs. The GluR $\delta 2$ mutant PC in Figure 8 was innervated by at least three distinct CFs. Stimulation of one CF (CF1) generated typical complex spike (Fig. $8 B$ ), whereas stimulation of other two CFs ( $C F 2$ and $C F 3$ ) elicited slow responses (Fig. $8 E, H)$. Stimulation of $\mathrm{CF} 1$ induced $\mathrm{Ca}^{2+}$ transients that spread over the entire dendritic tree involving both proximal and distal dendrites (Fig. 8C,D, R1-R6). In contrast, stimulation of CF2 induced $\mathrm{Ca}^{2+}$ transients that were confined to the distal portions $(R 4, R 5)$ of the left dendritic branch (Fig. $8 F, G)$. Stimulation of $\mathrm{CF} 3$ induced small $\mathrm{Ca}^{2+}$ transients that were confined to the most distal dendrites (R6) near the pial surface (Fig. 8I,J). Another GluR $\delta 2$ mutant PC shown in Figure 9 was innervated by at least three distinct CFs that generated a fast response (Fig. 9B, $C F 1$ ) and slow responses (Fig. $9 E, H, C F 2$ and $C F 3$ ). Stimulation of $\mathrm{CF} 1$ induced $\mathrm{Ca}^{2+}$ transients that spread over the middle dendritic tree and spared the small trees in the left and the right branches (Fig. $9 C, D)$. The $\mathrm{Ca}^{2+}$ rose in both proximal $(R 1, R 2)$ and distal $(R 4, R 5)$ portions of the middle dendritic tree (Fig. $9 C, D)$. Stimulation of $\mathrm{CF} 2$ induced $\mathrm{Ca}^{2+}$ transients that were confined to the distal portions $(R 5)$ of the right dendritic tree and spared its proximal $(R 1, R 2)$ portions (Fig. $9 F, G)$. Stimulation of $\mathrm{CF} 3$ induced $\mathrm{Ca}^{2+}$ transients that were confined to the left dendritic branch (Fig. 9I,J). The $\mathrm{Ca}^{2+}$ rose slightly in the tertiary dendrite $(R 3)$ and clearly in distal dendrites $(R 6)$ but showed no change in the primary dendrite (R1). In 24 GluR $\delta 2$ mutant PCs, we found that slow $\mathrm{CF}$ responses were always associated with $\mathrm{Ca}^{2+}$ transients that were confined to the distal dendrites. In a 
Figure 9. $\mathrm{CF}$-induced $\mathrm{Ca}^{2+}$ transients in another multiple-innervated GluR $\delta 2$ mutant PC. Reconstructed image of the $\mathrm{PC}(A)$, responses to $\mathrm{CF}$ stimulation $(B, E$, $H)$, time course of $\mathrm{Ca}^{2+}$ signals $(C, F, I)$, and pseudocolor images $(D, G, J)$ are illustrated in a manner similar to Figure 8. Scale bar, $20 \mu \mathrm{m}$.
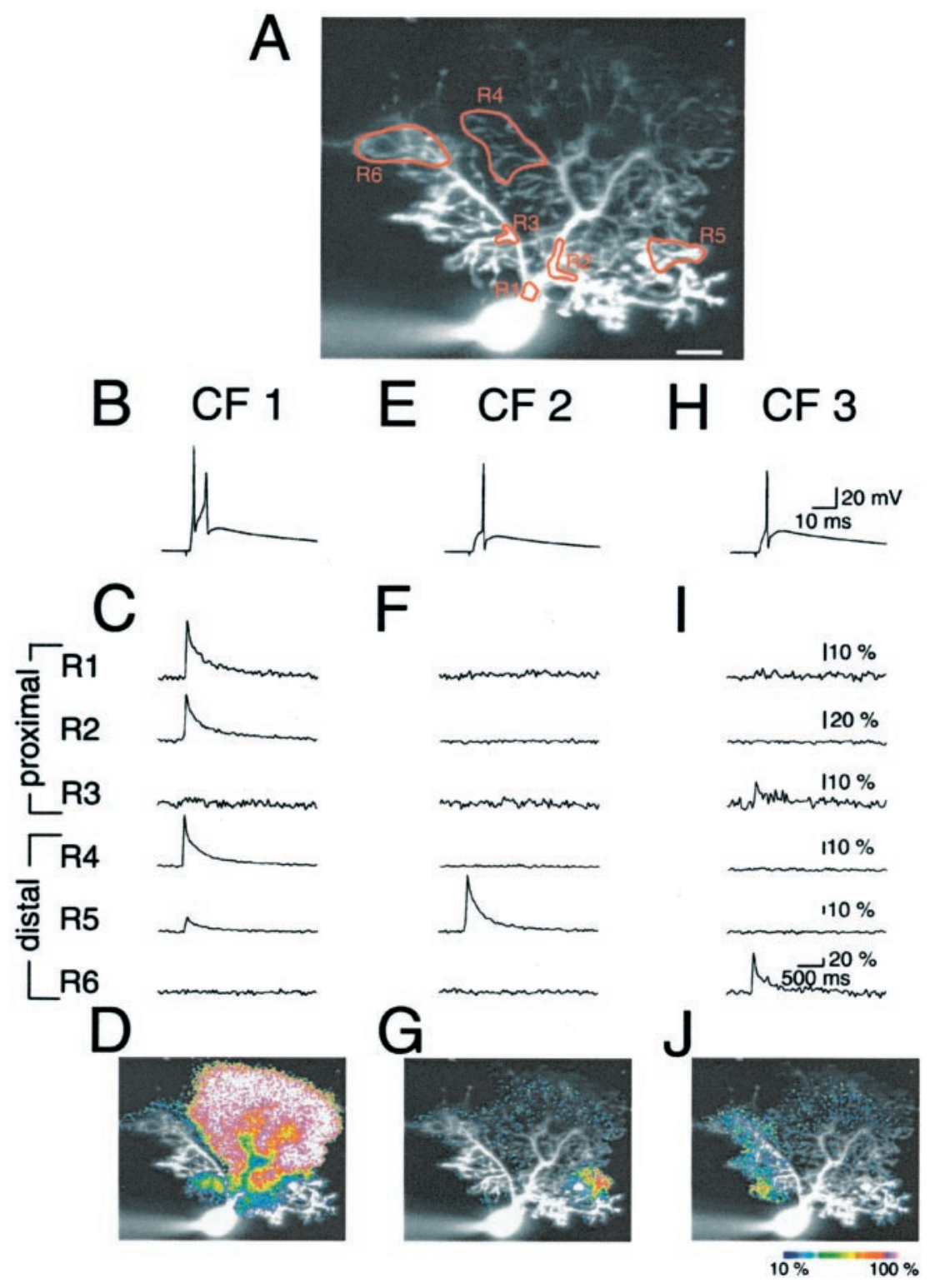

few slow $\mathrm{CF}$ responses, small $\mathrm{Ca}^{2+}$ signals could be detected also in the tertiary dendrites (Fig. 9, CF3); however, the $\mathrm{Ca}^{2+}$ transients never involved the primary dendrites. This pattern of CF-induced $\mathrm{Ca}^{2+}$ transients was observed in no PCs from the wild-type and in only one PC from the mGluR1 mutant.

To quantify the differences in $\mathrm{CF}$ innervation patterns, the distance from the soma to the dendrites with detectable $\mathrm{Ca}^{2+}$ signals was measured along the main dendrites (Fig. 10). As exemplified in Figure $10 A$, the actual dendritic branches were traced, and the shortest distance was measured from the origin of the primary dendrite to the most proximal point of the dendritic tree where the $\mathrm{Ca}^{2+}$ signal was detected. In CF responses of wild-type and mGluR1 mutant mice, the distance was almost 0 $\mu \mathrm{m}$ (Fig. $10 \mathrm{~B}$ ), indicating that the $\mathrm{Ca}^{2+}$ rose in the primary dendrite. In GluR $\delta 2$ mutant mice, the length was almost $0 \mu \mathrm{m}$ for the fast response, whereas it was $\sim 50 \mu \mathrm{m}$ on an average for the slow response (Fig. $10 B$ ). These results suggest that atypical slow CF responses of GluR $\delta 2$ PCs arise from synapses located on the distal dendrites.

\section{Morphology of CFs from GluR $\delta 2-$ and mGluR1-deficient mice}

To investigate the CF innervation patterns morphologically, anterogradely labeled CFs were visualized in parasagittal cerebellar sections (Fig. 11). Genotypic differences were noted in the extent of CF arbors within the molecular layer. Labeled CFs of GluR $\delta 2$ mutant mice extended up to more superficial regions of the molecular layer than those of wild-type and mGluR1 mutant mice (Fig. 11A-C). Because the thickness of the molecular layer is slightly reduced in GluR $\delta 2$ mutant mice (Kurihara et al., 1997), we evaluated the extent of CF arbors by measuring the height of the most distal tip of each labeled CF relative to the thickness of the molecular layer. We selected cerebellar sections from each mouse that contained staining of entire CF arbors from the Purkinje cell layer to the top of the molecular layer. Then, we examined at least 30 labeled CFs in the straight portion of the lobule VI. The most distal tip of CFs in GluR $\delta 2$ mutant mice reached $95.0 \pm 0.1 \%$ (mean $\pm \operatorname{SEM} ; n=3$ ) of the molecular layer thickness. This score was significantly higher than that of the 


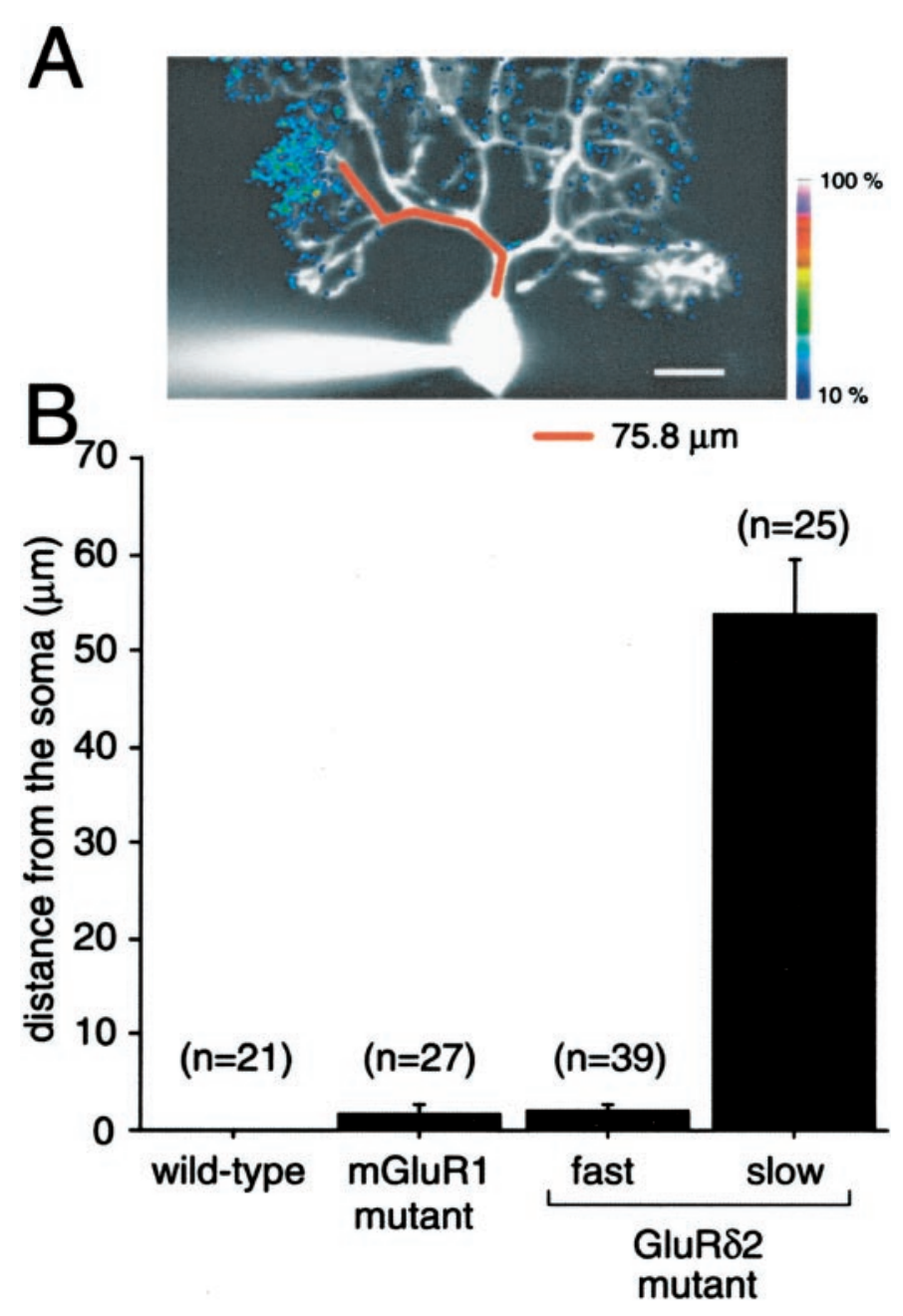

Figure 10. Distance from the soma to the dendrites with detectable $\mathrm{Ca}^{2+}$ signals. $A$, Pseudocolor image from the GluR $\delta 2$ mutant PC shown in Figure 9 exemplifying how the distance was measured. The actual dendritic branches were traced (thick red line), and the shortest distance was measured from the origin of the primary dendrite to the most proximal point of the dendritic tree where the $\mathrm{Ca}^{2+}$ signal was detected. The distance was $75.8 \mu \mathrm{m}$ in this case. Scale bar, $20 \mu \mathrm{m}$. B, Summary histogram of the distance from the soma for the three strains of mice.

wild-type $(83.1 \pm 0.5 \% ; n=3 ; p<0.0001)$ or the mGluR1 mutant $(77.8 \pm 0.7 \% ; n=3 ; p<0.0001)$ mouse. Our previous study indicates that PC dendrites extend to the surface of the molecular layer in GluR $\delta 2$ mutant mice as well as wild-type mice (Kurihara et al., 1997). Taken together, these results suggest that CFs of GluR $\delta 2$ mutant mice innervate more distal portions of PC dendrites than those of wild-type and mGluR1 mutant mice.

\section{DISCUSSION}

\section{Distinct CF innervation patterns in GluR $\delta 2$ mutant and mGluR1 mutant PCs}

GluR $\delta 2$ mutant PCs had atypical CF-EPSCs with slow 10-90\% rise times that coexisted with typical fast rise time CF-EPSCs, suggesting that slow CF-EPSCs arise from synapses located electrotonically distant from the soma. Imaging of $\mathrm{CF}$-induced $\mathrm{Ca}^{2+}$ signals through voltage-gated $\mathrm{Ca}^{2+}$ channels revealed that GluR $\delta 2$ mutant PCs had atypical small CF responses with $\mathrm{Ca}^{2+}$ signals that were confined to PC distal dendrites. In contrast, $\mathrm{CF}$-induced $\mathrm{Ca}^{2+}$ signals involved both proximal and distal den- drites in wild-type PCs. Morphologically, CFs of GluR $\delta 2$ mutant mice extended to the superficial regions of the molecular layer, whereas CFs of wild-type mice extended to the four-fifths of the molecular layer and spared the external one-fifth. On the other hand, the CF innervation pattern of mGluR1 mutant mice resembled that of the wild-type mice in the following respects: (1) CF-EPSCs had fast rise times ( $\leq 1 \mathrm{msec}$ ), (2) $\mathrm{CF}$-induced $\mathrm{Ca}^{2+}$ signals involved proximal dendrites, and (3) anterogradely labeled CFs extended to the four-fifths of the molecular layer and spared the external one-fifth.

Previous electron microscopic studies in mouse and rat indicate that CFs form extensive synaptic contacts on protuberance of the proximal dendrites of PCs, whereas PFs form en passant synapses on spines of the distal dendrites of PCs (Larramendi and Victor, 1967; Palay and Chan-Palay, 1974; Ito, 1984). Staining of CFs in rats also revealed that CFs innervate $\mathrm{PC}$ proximal dendrites (Strata and Rossi, 1998; Sugihara et al., 1999; Kreitzer et al., 2000). The range of CF-induced $\mathrm{Ca}^{2+}$ signals, however, does not precisely reflect the location of $\mathrm{CF}$ synapses on $\mathrm{PC}$ dendritic trees. Previous studies consistently indicate that $\mathrm{CF}$-induced $\mathrm{Ca}^{2+}$ transients spread over the entire dendritic tree of PCs involving both proximal and distal dendrites (Ross and Werman, 1987; Kano et al., 1992; Konnerth et al., 1992; Miyakawa et al., 1992; Eilers et al., 1995b). The $\mathrm{Ca}^{2+}$ transients in distal dendrites are thought to reflect the spread of depolarization from proximal dendrites. CF-EPSPs are generated at proximal dendrites of PCs. However, because they are quite large in size, they can readily activate voltage-gated $\mathrm{Ca}^{2+}$ channels not only at proximal dendrites but also at distal dendrites. In contrast, the $\mathrm{Ca}^{2+}$ transients induced by PF stimulation are confined to the distal dendrites, and the range of the $\mathrm{Ca}^{2+}$ signals reflects the site of PF synapses (Eilers et al., 1995a; Finch and Augustine, 1998; Takechi et al., 1998; Wang et al., 2000). This is presumably because PF-EPSPs are relatively small in size and can only activate voltage-gated $\mathrm{Ca}^{2+}$ channels locally at the site of PF-EPSP generation. The atypical CF responses in GluR $\delta 2$ mutant mice were also relatively small in size and presumed to induce $\mathrm{Ca}^{2+}$ signals that reflect the site of their generation. In these respects, the atypical CF responses resemble PF-mediated responses and presumably reflect synaptic activity at PC distal dendrites.

Taken together, the results of the present study suggest that surplus CFs persist in GluR $\delta 2$ mutant mice by forming ectopic synapses onto distal dendrites of PCs, whereas CFs of mGluR1 mutant mice form synapses onto PC proximal dendrites similar to wild-type mice.

\section{Roles of GluR $\delta 2$ in PF and CF synapse formation}

Our previous study in the GluR $\delta 2$ mutant indicates that the abnormality of PF synaptogenesis is not found at P7 but is evident at P14 and thereafter (Kurihara et al., 1997). Thus, the appearance of atypical slow CF-EPSCs coincides temporally with the manifestation of impaired PF synaptogenesis. Previous studies indicate that the developmental change in CF from multiple- to mono-innervation of cerebellar PCs depends on the presence of intact granule cells and the formation of PF to PC synapses (Woodward et al., 1974; Crépel and Mariani, 1976; Mariani et al., 1977; Crépel and Delhaye-Bouchaud, 1979; Crépel et al., 1980; Mariani and Changeux, 1980; Mariani et al., 1990; Bravin et al., 1995; Sugihara et al., 2000). Thus, impairment of PF to PC synapse formation in GluR $\delta 2$ mutant mice (Kashiwabuchi et al., 1995; Kurihara et al., 1997) can cause persistent multiple CF innervation. In wild-type mice, massive formation of $\mathrm{PF}$ to $\mathrm{PC}$ 

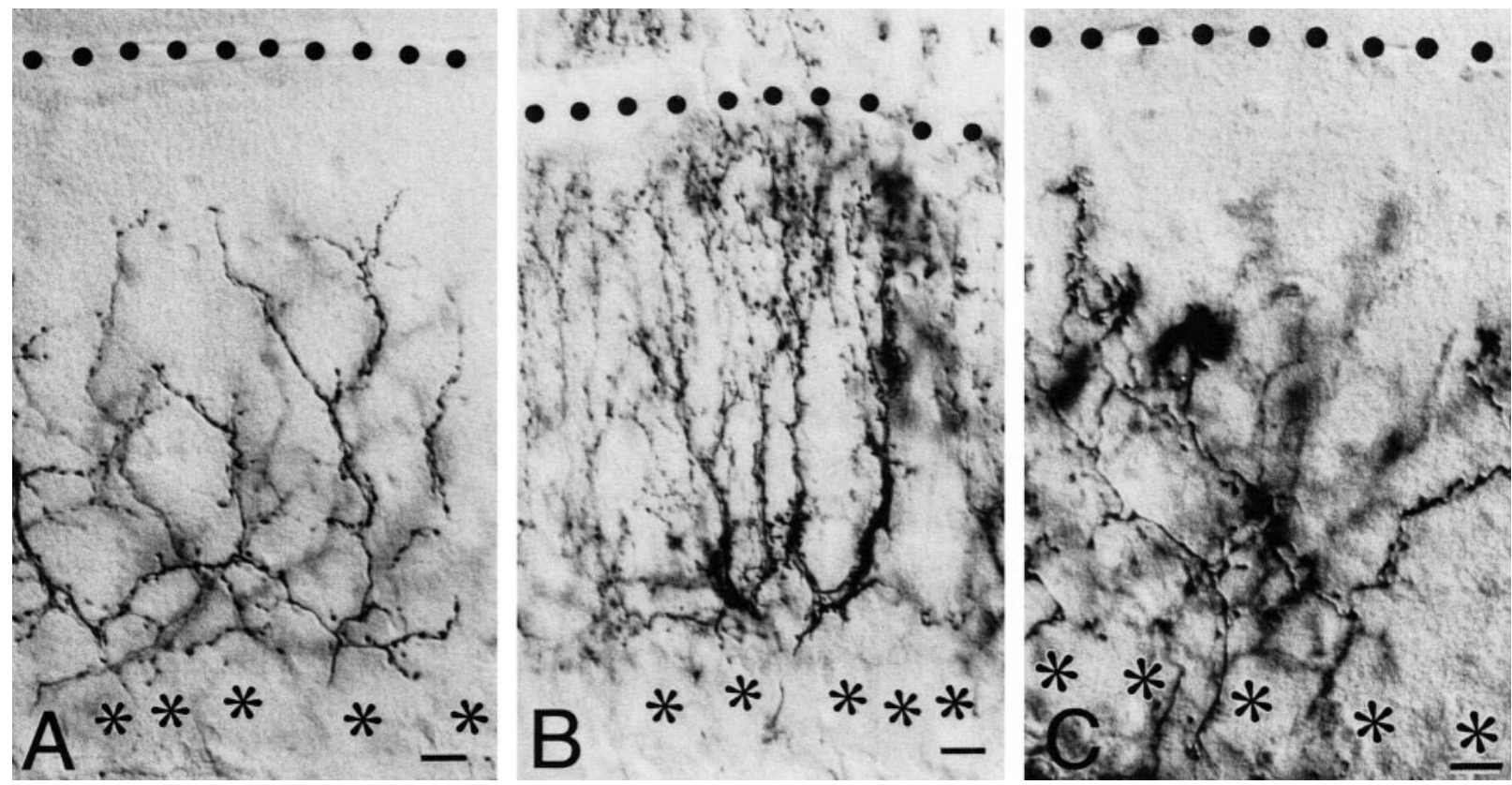

Figure 11. Anterogradely labeled CFs in the cerebellar lobule VI of the wild-type $(A)$, GluR $\delta 2$ mutant $(B)$, and mGluR1 mutant $(C)$ mice. Dotted lines in $A-C$ indicate the pial surface of the molecular layer. Asterisks indicates PC somata. Scale bars, $10 \mu \mathrm{m}$.

synapses occurs onto dendritic spines of PC distal dendrites during the second and third postnatal weeks. CF synapses may not be maintained at distal dendrites and become confined to the thick proximal dendrites. Then, a competition may follow between the remaining CFs for postsynaptic sites on the proximal dendrites, and finally, a single CF may survive to innervate the PC. In GluR $\delta 2$ mutant mice, CF synapses may remain at distal dendrites because of the impairment of PF to PC synapse formation during the second and third postnatal weeks. However, the competition may occur between CFs for postsynaptic sites on the proximal dendrites, and in the majority of PCs, one $\mathrm{CF}$ may win to form extensive synapses on the proximal dendrites. As a consequence, many PCs lacking GluR $\delta 2$ have one typical CF that generated fast CF-EPSCs and additional atypical CFs that generated slow CF-EPSCs.

A previous study indicates that the $\delta$ receptor immunoreactivity is prominent at CF synapses at P10 and P14 and then becomes weaker at later developmental stages (Zhao et al., 1998). On the other hand, $\delta$ receptors are abundant on postsynaptic membranes at PF synapses from P10 to adult (Takayama et al., 1995, 1996; Landsend et al., 1997; Zhao et al., 1998). Thus, the developmental stage at which the impaired PF synapse formation becomes obvious in GluR $\delta 2$ mutant mice corresponds well with the period during which the $\delta$ receptors are transiently expressed at $\mathrm{CF}$ synapses. These results suggest that GluR $\delta 2$ may also play active roles in CF synapse formation during P10-P14 in addition to stabilizing PF synapses.

It is reported that the spontaneously occurring ataxic mouse mutation lurcher is a gain-of-function mutation in the GluR $\delta 2$ gene (Zuo et al., 1997). Mutated GluR $\delta 2$ channels behave as depolarizing leak channels independent of glutamate. Consequently, PCs display a very high membrane conductance and are constitutively depolarized and, perhaps, permit continuous $\mathrm{Ca}^{2+}$ inflow. This appears to disturb various signal transduction cascades within PCs, including the pathway from mGluR1 to the $\gamma$ isoform of protein kinase $\mathrm{C}(\mathrm{PKC} \gamma)$ that is shown to be required for CF synapse elimination (Kano et al., 1995, 1997, 1998; Offermanns et al., 1997; Hashimoto et al., 2000). This may be a cause of persistent multiple CF innervation in lurcher mutant mice (Rabacchi et al., 1992). We studied the kinetics of CF-EPSCs in lurcher mice, but atypical slow CF-EPSCs abundant in GluR $\delta 2$ mutant mice were not found (K. Hashimoto and M. Kano, unpublished observation).

\section{Roles of mGluR1 in CF synapse elimination}

We have reported that multiple $\mathrm{CF}$ innervation persists into adulthood in four strains of mutant mice lacking mGluR1 (Kano et al., 1997), G-protein $\alpha \mathrm{q}$ subunit (G $\alpha \mathrm{q}$ ) (Offermanns et al., 1997; Hashimoto et al., 2000), phospholipase C $\beta 4$ (PLC $\beta 4$ ) (Kano et al., 1998; Hashimoto et al., 2000), and PKC $\gamma$ (Kano et al., 1995) caused by the defects in CF synapse elimination during the third postnatal week. In contrast to GluR $\delta 2$ mutant mice, these mutant mice have normal PF-PC synaptogenesis and normal rise time of the CF-EPSCs. We also found that blockade of NMDA receptors during $\mathrm{P} 15$ and $\mathrm{P} 16$, but not before or after this period, resulted in a higher incidence of multiple $\mathrm{CF}$ innervation and caused a mild but persistent loss of motor coordination (Kakizawa et al., 2000). Neither basic synaptic functions nor cerebellar morphology was affected by this manipulation. During $\mathrm{P} 15$ and P16, NMDA receptors were not functional at either PF to $\mathrm{PC}$ or $\mathrm{CF}$ to $\mathrm{PC}$ synapses but were rich in mossy fiber to granule cell synapses (Kakizawa et al., 2000). We also demonstrated that the mGluR1 to PKC $\gamma$ cascade must work within PCs to complete CF synapse elimination (Ichise et al., 2000). We introduced the mGluR1 transgene into mGluR1-null mutant mice using a PC-specific promoter, L7. The mGluR1-rescue mice showed normal regression of multiple CF innervation and apparently normal motor coordination (Ichise et al., 2000). These results suggest that the signal transduction cascade from mGluR1 to PKC $\gamma$ is activated at PF-PC synapses (Kano et al., 1995, 1997) in a manner dependent on NMDA receptor-mediated activity at mossy fiber to granule cell synapses (Kakizawa et al., 2000). 
In GluR $\delta 2$ mutant mice a substantial number of PCs had multiple CF-EPSCs with fast rise-times in addition to atypical slow CF-EPSCs (Fig. 3). It is possible that the impaired PF-PC synapse formation in GluR $\delta 2$ mutant leads to a reduction of PF-induced drive of mGluR1 and causes persistent multiple CF innervations that are similar to those of the mGluR1, G $\alpha \mathrm{q}$, PLC $\beta 4$, and PKC $\gamma$ mutant PCs.

In conclusion, we propose that GluR $\delta 2$ is required for consolidating PF synapses onto PC distal dendrites and restricting CF synapses to the proximal dendritic domain, whereas the mGluR1 to $\mathrm{PKC} \gamma$ signaling pathway is involved in eliminating excess $\mathrm{CF}$ synapses at the proximal dendrites. By the actions of these two glutamate receptors, synaptic connections of PCs mature normally during postnatal cerebellar development.

\section{REFERENCES}

Aiba A, Kano M, Chen C, Stanton ME, Fox GD, Herrup K, Zwingman TA, Tonegawa S (1994) Deficient cerebellar long-term depression and impaired motor learning in mGluR1 mutant mice. Cell 79:377-388.

Altman J, Bayer SA (1997) Development of the cerebellar system. Boca Raton, FL: CRC.

Araki K, Meguro H, Kushiya E, Takayama C, Inoue Y, Mishina M (1993) Selective expression of the glutamate receptor channel delta 2 subunit in cerebellar Purkinje cells. Biochem Biophys Res Commun 197:1267-1276.

Baude A, Nusser Z, Roberts JD, Mulvihill E, McIlhinney RA, Somogyi P (1993) The metabotropic glutamate receptor (mGluR1 $\alpha$ ) is concentrated at perisynaptic membrane of neuronal subpopulations as detected by immunogold reaction. Neuron 11:771-787.

Bravin M, Rossi F, Strata P (1995) Different climbing fibres innervate separate dendritic regions of the same Purkinje cell in hypogranular cerebellum. J Comp Neurol 357:395-407.

Conquet F, Bashir ZI, Davies CH, Daniel H, Ferraguti F, Bordi F, Franz-Bacon K, Reggiani A, Matarese V, Conde F, Collingridge GL, Crépel F (1994) Motor deficit and impairment of synaptic plasticity in mice lacking mGluR1. Nature 372:237-243.

Crépel F (1982) Regression of functional synapses in the immature mammalian cerebellum. Trends Neurosci 5:266-269.

Crépel F, Delhaye-Bouchaud N (1979) Distribution of climbing fibers on cerebellar Purkinje cells in X-irradiated rats. An electrophysiological study. J Physiol (Lond) 290:97-112.

Crépel F, Mariani J (1976) Multiple innervation of Purkinje cells by climbing fibers in the cerebellum of the weaver mutant mouse. J Neurobiol 7:579-582.

Crépel F, Delhaye-Bouchaud N, Gustavino JM, Sampaio I (1980) Multiple innervation of cerebellar Purkinje cells by climbing fibres in staggerer mutant mouse. Nature 283:483-484.

Edwards FA, Konnerth A, Sakmann B, Takahashi T (1989) A thin slice preparation for patch-clamp recordings from neurons of the mammalian central nervous system. Pflügers Arch 414:600-612.

Eilers J, Augustine GJ, Konnerth A (1995a) Subthreshold synaptic Ca ${ }^{2+}$ signalling in fine dendrites and spines of cerebellar Purkinje neurons. Nature 373:155-158.

Eilers J, Callewaert C, Armstrong C, Konnerth A (1995b) Calcium signaling in a narrow somatic submembrane shell during synaptic activity in cerebellar Purkinje neurons. Proc Natl Acad Sci USA 92:10272-10276.

Finch EA, Augustine GJ (1998) Local calcium signalling by inositol1,4,5-trisphosphate in Purkinje cell dendrites. Nature 396:753-756.

Hashimoto K, Kano M (1998) Presynaptic origin of paired-pulse depression at climbing fibre to Purkinje cell synapses in the rat cerebellum. J Physiol (Lond) 506:391-405.

Hashimoto K, Watanabe M, Kurihara H, Offermanns S, Jiang H, Wu Y, Jun K, Shin HS, Inoue Y, Wu D, Simon M I, Kano M (2000) Climbing fiber synapse elimination during postnatal cerebellar development requires signal transduction involving $\mathrm{G} \alpha \mathrm{q}$ and phospholipase $\mathrm{C} \beta 4$. Prog Brain Res 124:31-48.

Hirano T, Kasono K, Araki K, Mishina M (1995) Suppression of LTD in cultured Purkinje cells deficient in the glutamate receptor delta 2 subunit. NeuroReport 6:524-526.

Ichise T, Kano M, Hashimoto K, Yanagihara D, Nakao K, Shigemoto R, Katsuki M, Aiba A (2000) mGluR1 in cerebellar Purkinje cells essential for long-term depression, climbing fiber synapse elimination and motor coordination. Science 288:1832-1835.

Ito M (1984) The cerebellum and neural control. New York: Raven.

Kakizawa S, Yamasaki M, Watanabe M, Kano M (2000) Critical period for activity-dependent synapse elimination in developing cerebellum. J Neurosci 20:4954-4961

Kano M, Konnerth A (1992) Cerebellar slices for patch clamp recording.
In: Practical electrophysiological methods (Kettenmann H, Grantyn R, eds), pp 54-57. New York: Wiley.

Kano M, Rexhausen U, Dreessen J, Konnerth A (1992) Synaptic excitation produces a long-lasting rebound potentiation of inhibitory synaptic currents in cerebellar Purkinje cells. Nature 356:601-604.

Kano M, Hashimoto K, Chen C, Abeliovich A, Aiba A, Kurihara H, Watanabe M, Inoue Y, Tonegawa S (1995) Impaired synapse elimination during cerebellar development in PKC $\gamma$ mutant mice. Cell 83:1223-1231.

Kano M, Hashimoto K, Kurihara H, Watanabe M, Inoue Y, Aiba A, Tonegawa S (1997) Persistent multiple climbing fiber innervation of cerebellar Purkinje cells in mice lacking mGluR1. Neuron 18:71-79.

Kano M, Hashimoto K, Watanabe M, Kurihara H, Inoue Y, Offermanns S, Jiangs H, Wu Y, Jun K, Shin H-S, Simon MI, Wu D (1998) PLCß4 is specifically involved in climbing fiber synapse elimination in the developing cerebellum. Proc Natl Acad Sci USA 95:15724-15729.

Kashiwabuchi N, Ikeda K, Araki K, Hirano T, Shibuki K, Takayama C, Inoue Y, Kutsuwada T, Yagi T, Kang Y, Aizawa S, Mishina M (1995) Impairment of motor coordination, Purkinje cell synapse formation, and cerebellar long-term depression in GluR $\delta 2$ mutant mice. Cell $81: 245-252$

Konnerth A, Llano I, Armstrong CM (1990) Synaptic currents in cerebellar Purkinje cells. Proc Natl Acad Sci USA 87:2662-2665.

Konnerth A, Dreessen J, Augustine GJ (1992) Brief dendritic calcium signals initiate long-lasting synaptic depression in cerebellar Purkinje cells. Proc Natl Acad Sci USA 89:7051-7055.

Kreitzer AC, Gee KR, Archer EA, Regehr WG (2000) Monitoring presynaptic calcium dynamics in projection fibers by in vivo loading of novel calcium indicator. Neuron 27:25-32.

Kurihara H, Hashimoto K, Kano M, Takayama C, Sakimura K, Mishina M, Inoue Y, Watanabe M (1997) Impaired parallel fiber-Purkinje cell synapse stabilization during cerebellar development of mutant mice lacking the glutamate receptor $\delta 2$ subunit. J Neurosci 17:9613-9623.

Landsend AS, Amiry-Moghaddam M, Matsubara A, Bergersen L, Usam S, Wenthold RJ, Ottersen OP (1997) Differential localization of $\delta 2$ glutamate receptors in the rat cerebellum: coexpression with AMPA receptors in parallel fiber-spine synapses and absence from climbing fiber-spine synapses. J Neurosci 17:834-842.

Larramendi LMH, Victor T (1967) Synapses on the Purkinje cell spines in the mouse. An electron microscopic study. Brain Res 5:15-30.

Lévénès C, Daniel H, Jaillard D, Conquet F, Crépel F (1997) Incomplete regression of multiple climbing fibre innervation of cerebellar Purkinje cells in mGluR1 mutant mice. NeuroReport 20:571-574.

Llano I, Marty A, Armstrong CM, Konnerth A (1991) Synaptic- and agonist-induced excitatory currents of Purkinje cells in rat cerebellar slice. J Physiol (Lond) 434:183-213

Lomeli H, Sprengel R, Laurie DJ, Köhr G, Herb A, Seeburg PH, Wisden W (1993) The rat delta- 1 and delta-2 subunits extend the excitatory amino acid receptor family. FEBS Lett 315:318-322.

Mariani J, Changeux JP (1980) Multiple innervation of Purkinje cells by climbing fibers in the cerebellum of the adult staggerer mutant mouse. J Neurobiol 11:41-50.

Mariani J, Crépel F, Mikoshiba K, Changeux JP, Sotelo C (1977) Anatomical, physiological and biochemical studies of the cerebellum from reeler mutant mouse. Philos Trans R Soc Lond B Biol Sci 281:93-97.

Mariani J, Benoit P, Hoang MD, Thomson M-A, Delhaye-Bouchaud N (1990) Extent of multiple innervation of cerebellar Purkinje cells by climbing fibers in X-irradiated rats. Comparison of different schedules of irradiation during the first postnatal week. Dev Brain Res 57:63-70.

Miyakawa H, Lev-Ram V, Lasser-Ross N, Ross WN (1992) Calcium transients evoked by climbing fiber and parallel fiber synaptic inputs in guinea pig cerebellar Purkinje neurons. J Neurophysiol 68:1178-1189.

Nusser Z, Mulvihill E, Streit P, Somogyi P (1994) Subsynaptic segregation of metabotropic and ionotropic glutamate receptors as revealed by immunogold localization. Neuroscience 61:421-427.

Offermanns S, Hashimoto K, Watanabe M, Sun W, Kurihara H, Thompson RF, Inoue Y, Kano M, Simon MI (1997) Impaired motor coordination and persistent multiple climbing fiber innervation of cerebellar Purkinje cells in mice lacking G $\alpha \mathrm{q}$. Proc Natl Acad Sci USA 94:14089-14094

Palay SL, Chan-Palay V (1974) Cerebellar cortex. Cytology and organization. New York: Springer.

Rabacchi S, Bailly Y, Delhaye-Bouchaud N, Herrup K, Mariani J (1992) Role of the target in synapse elimination: studies in cerebellum of developing Lurcher mutants and adult chimeric mice. J Neurosci 12:4712-4720.

Ross WN, Werman R (1987) Mapping calcium transients in the dendrites of Purkinje cells from the guinea-pig cerebellum in vitro. J Physiol (Lond) 389:319-336.

Rossi F, Jankovski A, Sotelo C (1995) Target neuron controls the integrity of afferent axon phenotype: a study on the Purkinje cell-climbing fiber system in cerebellar mutant mice. J Neurosci 15:2040-2056.

Strata P, Rossi F (1998) Plasticity of the olivocerebellar pathway. Trends Neurosci 21:407-413.

Sugihara I, Wu H-S, Shinoda Y (1999) Morphology of single olivocer- 
ebellar axons labeled with biotinylated dextran amine in the rat. J Comp Neurol 414:131-148.

Sugihara I, Bailly Y, Mariani J (2000) Olivocerebellar climbing fibers in the granuloprival cerebellum: morphological study of individual axonal projections in the x-irradiated rat. J Neurosci 20:3745-3760.

Takayama C, Nakagawa S, Watanabe M, Mishina M, Inoue Y (1995) Light- and electron-microscopic localization of the glutamate receptor channel delta 2 subunit in the mouse Purkinje cell. Neurosci Lett 188:89-92.

Takayama C, Nakagawa S, Watanabe M, Mishina M, Inoue Y (1996) Developmental changes in expression and distribution of the glutamate receptor channel $\mathrm{d} 2$ subunit according to the Purkinje cell maturation. Dev Brain Res 92:147-155.

Takechi H, Eilers J, Konnerth A (1998) A new class of synaptic response involving calcium release in dendritic spines. Nature 396:757-760.

Wang SSH, Khirong L, Augustine GJ (2000) Quantification of spread of cerebellar long-term depression with chemical two-photon uncaging of glutamate. Proc Natl Acad Sci USA 97:8635-8640.
Watase K, Hashimoto K, Kano M, Yamada K, Watanabe M, Inoue Y, Okuyama S, Sakagawa T, Ogawa S-I, Kawashima N, Hori S, Takimoto M, Wada K, Tanaka K (1998) Motor discoordination and increased susceptibility to cerebellar injury in GLAST mutant mice. Eur J Neurosci 10:976-988.

Woodward DJ, Hoffer BJ, Altman J (1974) Physiological and pharmacological properties of Purkinje cells in rat cerebellum degranulated by postnatal X-irradiation. J Neurobiol 5:283-304.

Yagi T, Tokunaga T, Furuya Y, Nada S, Yoshida M, Tsukada T, Saga Y, Takeda N, Ikawa Y, Aizawa S (1993) A novel ES cell line, TT2, with high germline-differentiating potency. Anal Biochem 214:70-76.

Zhao H-M, Wenthold RJ, Petralia RS (1998) Glutamate receptor targeting to synaptic populations on Purkinje cells is developmentally regulated. J Neurosci 18:5517-5528.

Zuo J, De Jager PL, Takahashi KA, Jiang W, Linden DJ, Heintz N (1997) Neurodegeneration in Lurcher mice caused by mutation in delta2 glutamate receptor gene. Nature 388:769-773. 